\title{
A systematic review of automated pre-processing, feature extraction and classification of cardiotocography
}

\author{
Shahad Al-yousif ${ }^{\text {Corresp., } 1,2}$, Ariep Jaenul ${ }^{3}$, Wisam Al-Dayyeni $^{1}$, A.h. Alamoodi ${ }^{4}$, Ihab Jabori ${ }^{5}$, Nooritawati Md Tahir ${ }^{6}$, \\ Ali Amer Ahmed Alrawi ${ }^{7}$, Zafer Cömert ${ }^{8}$, Nael A. Al-shareefi ${ }^{9}$, Abbadullah H. Saleh ${ }^{10}$ \\ ${ }^{1}$ Department of Medical Instrumentations Engineering Techniques, Dijlah University, Baghdad, Iraq \\ 2 Faculty of Information Science \& Engineering, Management and Science University, Shah Alam, selangoor, Malaysia \\ 3 Department of Electrical Engineering, Faculty of Engineering and Computer Science, Jakarta Global University, Jakarta, Indonesia \\ 4 Department of Computing, Universiti Pendidikan Sultan Idris, Tanjong Malim, Perak, Malaysia \\ 5 Faculty of Engineering, Tikrit University, Tikrit, Iraq \\ 6 Faculty of Electrical Engineering, Universiti Teknologi MARA (UiTM), Shah Alam, Selangor, Malaysia \\ 7 Training Directorate, Ministry of Science and Technology, Baghdad, Aljadireyah, Iraq \\ 8 Department of Software Engineering, Samsun University,, Samsun, Samsun, Turkey \\ 9 College of Biomedical Informatics, University of Information Technology and Communications (UOITC),, Baghdad, Almansoor, Iraq \\ 10 Department Computer Engineering, Karabük University,, Karabük, Karabük, Turkey \\ Corresponding Author: Shahad Al-yousif \\ Email address: shahad.alyousif@duc.edu.iq
}

Context: The interpretations of cardiotocography (CTG) tracings are indeed vital to monitor fetal well-being both during pregnancy and childbirth. Currently, many studies are focusing on feature extraction and CTG classification using computer vision approach in determining the most accurate diagnosis as well as monitoring the fetal well-being during pregnancy. Additionally, a fetal monitoring system would be able to perform detection and precise quantification of fetal heart rate patterns. Objective: This study aimed to perform a systematic review to describe the achievements made by the researchers, summarizing findings that have been found by previous researchers in feature extraction and CTG classification, to determine criteria and evaluation methods to the taxonomies of the propose literature in the CTG field and to distinguish aspects from relevant research in the field of CTG. Methods: Article search was done systematically using three databases: IEEE Xplore digital library, Science Direct, and Web of Science over a period of 5 years. The literature in the medical sciences and engineering was included in the search selection to provide a broader understanding for researchers. Results: After screening 372 articles, and based on our protocol of exclusion and inclusion criteria, as for final set of articles 50 articles were obtained. The research literature taxonomy was divided into four stages. First stage discussed the proposed method which presented steps and algorithms in the preprocessing stage, feature extraction and classification as well as their use in CTG (20/50 papers). The second stage included the development of system specifically on automatic Peer] Comput. Sci. reviewing PDF | (CS-2020:09:53118:1:1:NEW 10 Feb 2021) 
feature extraction and CTG classification (7/50 papers). The third stage consisted of reviews and survey articles on automatic feature extraction and CTG classification (3/50 papers). The last stage discussed evaluation and comparative studies to determine the best method for extracting and classifying features with comparisons based on a set of criteria (20/50 articles). Discussion: This study focused more on literature compared to techniques or methods. Also, this study conducts research and identification of various types of datasets used in surveys from publicly available, private, and commercial datasets. To analyze the results, researchers evaluated independent datasets using different techniques. Conclusions: This systematic review contributes to understand and have insight into the relevant research in the field of CTG by surveying and classifying pertinent research efforts. This review will help to address the current research opportunities, problems and challenges, motivations, recommendations related to feature extraction and CTG classification, as well as the measurement of various performance and various data sets used by other researchers. 


\title{
Automated pre-processing, feature extraction and classification of cardiotocography: a systematic review
}

Shahad Al-yousif ${ }^{* 2}$, Ariep Jainul ${ }^{3}$, Wisam Al-Dayyeni ${ }^{1}$, A.H. Alamoodi ${ }^{4}$, Ihab Jabori ${ }^{5}$ ,Nooritawati Md Tahir ${ }^{6}$, Ali Amer Ahmed Alrawi ${ }^{7}$, Zafer Cömert ${ }^{8}$, Nael A. Al-Shareefi ${ }^{9}$, Abbadullah H. Saleh ${ }^{10}$

1 Department of Medical Instrumentations Engineering Techniques, Dijlah University, Baghdad, Iraq.

2 Faculty of Information Science \& Engineering, Management and Science University, Shah Alam, Malaysia.

3 Department of Electrical Engineering, Faculty of Engineering and Computer Science, Jakarta Global University, Jakarta, Indonesia

4 Department of Computing, Universiti Pendidikan Sultan Idris, Tanjong Malim, Perak, Malaysia 5 Faculty of Engineering, Tikrit University, Iraq.

6 Faculty of Electrical Engineering, Universiti Teknologi MARA (UiTM), Selangor, Malaysia.

7 Ministry of Science and Technology, Training Directorate, Baghdad Iraq.

8 Department of Software Engineering, Samsun University, Samsun, Turkey.

9 College of Biomedical Informatics, University of Information Technology and Communications (UOITC), Baghdad, Iraq.

10 Department Computer Engineering Karabük University, Karabük, Turkey

Shahad.alyousif@duc.edu.iq,ariep@,itkj.ac.id,wisam.talib@duc.edu.iq,alamoodi@,fskik.upsi.edu. my, ihab@tu.edu.iq, nooritawati@,ieee.org, training.most@mohesr.gov.iq, zcomert@samsun.edu.tr, dr.nael.al_shareefi@uoitc.edu.iq, ahsm.8687@gmail.com,

\begin{abstract}
Context: The interpretation of cardiotocography tracings is indeed vital to monitor fetal wellbeing both during pregnancy and childbirth. Currently, many studies are focusing on feature extraction and cardiotocography classification using computer assistance in order to determine highest accurate of diagnosis for monitoring fetal wellbeing during pregnancy. Additionally, a fetal monitoring system using computer assistance allows accurate detection and precise quantification of fetal heart rate patterns.
\end{abstract}

Objective: This study aimed to perform a systematic review to describe the achievements made by the researchers, summarizing findings that have been found by previous researchers in feature 
extraction and cardiotocography classification, to determine criteria and evaluation methods to the taxonomies of the propose literature in the cardiotocography field and to distinguish aspects from relevant research in the field of cardiotocography.

Methods: Article search was done systematically using three databases: IEEE Xplore digital library, Science Direct and Web of Science over a period of 5 years (from 2013 to 2018). The literature in the medical sciences and engineering was included in the search selection to provide a broader understanding for researchers.

Results: After screening 372 articles, and based on our protocol of exclusion and inclusion criteria, as for final set of articles 50 articles were obtained. The research literature taxonomy was divided into four stages. First stage (stage 1) discussed the proposed method which presents algorithms in the pre-processing method, feature extraction and classification as well as their use in cardiotocography (20/50 articles). The second stage (stage 2 ) included the development of system specifically on automatic feature extraction and cardiotocography classification (7/50 articles). The third stage (stage 3) consisted of reviews and survey articles on automatic feature extraction and cardiotocography classification (3/50 articles). The last stage (stage 4) discussed evaluation and comparative studies to determine the best method for extracting and classifying features with comparisons based on a set of criteria (20/50 articles).

Discussion: This study focused more on literature compared to techniques or methods. Also, this study conducts research and identification of various types of datasets used in surveys from publicly available, private, and commercial datasets (we got 13 sources in total). To analyze the results, researchers evaluated independent datasets using different techniques. In total, six validation techniques that has been used are discussed in this review. Moreover, to measure the effectiveness of the classification method, classifier performance evaluation is performed using 22 various measurements.

Conclusions: This systematic review contributes to understand and have insight into the relevant research in the field of cardiotocography by surveying and classifying pertinent research efforts. This review will help to address the current research opportunities, problems and challenges, motivations, recommendations related to feature extraction and cardiotocography classification, as well as the measurement of various performance and various data sets used in research. 
67 This research is directed to specialists in gynecology and technicians in the field of medical 68 engineering to update them with the latest medical research in this field.

70 Keywords: Cardiotocography, Fetal Heart Rate, baseline, variability, Feature extraction,

71 Classification, uterine contraction and diagnoses.

72 Correspondence Author: shahad.alyousif@duc.edu.iq

\section{INTRODUCTION}

Every mother wants a healthy pregnancy, normal birth pregnancy and a healthy baby. This condition must be supported with regular prenatal care. For a mother, examinations are essential for detecting if there are any problems in pregnancy, preparing physically and mentally, knowing the condition of the pregnancy, and to determine the method of delivery that is in accordance with the results of the test. The purpose of CTG recordings is to identify when there is concern about fetal well-being to allow interventions to be carried out before the fetus is harmed. The focus is on identifying fetal heart rate (FHR) patterns associated with inadequate oxygen supply to the fetus. As for fetal testing is important to ensure the exact condition of the fetal so that high-risk births could be minimized, and Cardiotocography is one way to conduct prenatal testing [1].

Generally, cardiotocography is a practical method that can be used to examine fetal well-being and at the same time widely used for intrapartum and antepartum fetal monitoring [2-4]. Cardiotocography (CTG) is also called Electronic Fetal Monitoring (EFM), EFM was first introduced around 1960, and became the first tool to use phonocardiography to record Fetal Heart Rate (FHR), and was then replaced by a doppler signal with significant improvements to signal quality [5]. In addition, cardiotocography is the main biophysical method for monitoring the condition of the fetus during pregnancy and childbirth. CTG consists of non-invasive recording (using the doppler ultrasound technique) from changes in FHR and analyzes the relationship between fetal movement and maternal uterine contractions [6]. Information obtained from CTG is further used as an initial identification of pathological conditions (for instance fetal suffering, congenital heart deficiency, hypoxia and others) and can assist doctors to anticipate further for any complications and early permanent damage to the fetus [7]. 
96 From the recorded data attained using CTG, the obstetrician can extract and evaluate four 97 parameters which form the basis of CTG feature extraction based on international medical 98 guidelines $[8,9]$. These parameters are:

99 - Baseline - represents the physiological value with a range of 110 - 160 b.p.m, and if the 100 baseline is more than 160 b.p.m, the baseline is called tachycardia, whereas if the baseline is 101 below 110 b.p.m, the baseline is called bradycardia.

- Acceleration increases in the baseline higher than 15 b.p.m for at least 15 seconds. In 15 minutes, the acceleration must occur at least twice. At night acceleration is considered a pathological state and can also be considered as a response to fetal movement.

- Deceleration - Decrease in the baseline of more than 15 b.p.m at least 15 seconds. If deceleration is perceived with contraction, possibility indicates with hypoxia.

- Variability - Fluctuation of the baseline and is not considered as acceleration or deceleration. There are differences between variability during sleep state and perform activities or in active state.

110 Conversely, FHR signal monitoring is carried out by the obstetrician using eye inspection during

111 the critical labor period to assess the condition of the fetus [10]. However, the interpretations made

112 by humans are inconsistent namely about the traces and variability of inter and intra high observers

113 [11-14]. The interpreted results are subjective and cannot be reproduced. This is the starting point

114 for the debate on the effectiveness of cardiotocography in gynecology work or not, particularly in

115 the cases of low-risk pregnancies. In addition, this results is too dependent on the test which may

116 lead to increase in diagnosis errors from fetal distress and further increases the number of cesarean

117 deliveries [15]. Despite the developing in CTG guidelines to evaluate the recording of

118 cardiotocography, a misdiagnosis still occur because of the difference in experience and tacit

119 knowledge among obstetricians is a big dilemma [16].

120 To increase the assessment objectivity and repeatability, the computer-aided fetal monitoring 121 systems provide an automated quantitative analysis of the signals. It allows for accurate detection 122 and precise quantification of the FHR patterns and provides additional information that is invisible 123 to the naked eye $[17,18]$. Analysis and classification of cardiotocography using computerized 124 systems are widely applied to increase the effectiveness and utility of CTG monitoring and also 
125 reducing inconsistencies in interpretation, many efforts have been made by researchers from

126 medical and technical backgrounds [19].

127 Our research aims to describe the achievements made by the researchers, summarizing findings

128 that have been found by previous researchers in preprocessing, feature extraction and

129 cardiotocography classification, to determine assessment methods and criteria, to suggest literature

130 taxonomies in the CTG field and to distinguish aspects from relevant research in the field of

131 cardiotocography. The preparation in this study was carried out in this way: Sec. 1 introduces the

132 field of research that we are doing; Sec. 2 describes the protocol of the proposed systematic review;

133 the taxonomy style is presented in Sec. 3; statistical results of the articles reviewed is elaborated

134 in Sec. 4; Sec. 5 discusses guidelines, data sets, validation techniques, and measures of 135 performance, motivation, challenges, and recommendations taken from articles reviewed; Sec. 6

136 discussed limitations of the study; and in Sec. 7 findings from this reviews are concluded.

\section{2. SYSTEMATIC REVIEW SOURCES}

\section{2.1. Database}

140 Article search is done systematically using three databases such as (1) IEEE Xplore digital library,

141 (2) Science Direct and (3) Web of Science (WOS). Article searches are based on the facilities

142 provided by the three databases both in simple and complex searches by searching for various 143 journals and conference articles in various fields of science such as engineering, computer science 144 and medical. Therefore, the literature in the medical sciences and engineering is included in the 145 search scope to provide broader understanding and views for researchers related to a variety of 146 science majors.

\section{2.2. Article Selection Procedure}

148 The selection procedure of the article in this study was based on an intensive search for the 149 relevant publications in this field of study using the following steps: (1) Scan titles and abstracts 150 that are in accordance with the topic and exclude inappropriate and not related papers and to find 151 any duplication of papers. (2) The next step is to read the full papers thoroughly. 


\section{$152 \quad$ 2.3. Article Search}

153 The articles search was conducted using three databases namely IEEE, Science Direct (SD) and

154 Web of Science (WoS) through the database search on March 17, 2018. In all three databases,

155 searches were performed using queries (Cardiotocogram OR Cardiotocograph OR

156 Cardiotocography) with the following keywords ("fetal heart rate" OR baseline OR "baseline

157 variability" OR acceleration OR deceleration OR "uterine contractions"). Searches are added using

158 this keyword ("FHR-monitoring" OR "feature extraction" OR classification OR diagnosis) to limit

159 the search space to cardiotocography cases related to engineering and computer science. Search

160 queries are shown in Fig 1.

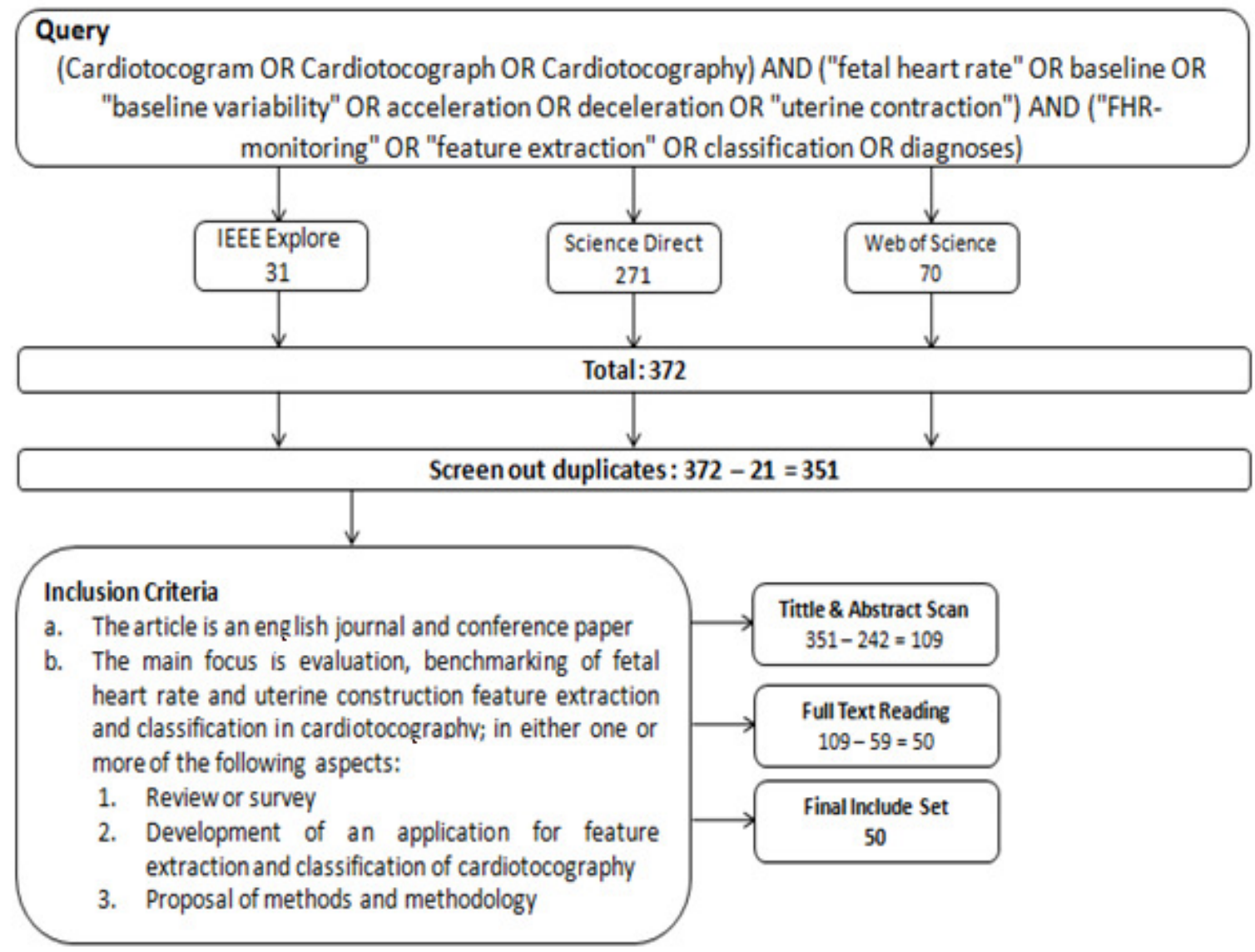

161

162

163

164

165

166

Fig. 1 Article selection, search query and inclusion criteria

Article searches are added with advanced search options for each database used to select conference and journals articles, and excluded articles from each chapter of the book or other documents. Articles in journals and conference articles are chosen for consideration because 
167 articles in journals and conferences are most likely involved in the latest research and relevant to 168 this study. The presentation of rule information used in conducting search requests is shown in 169 table 1.

Tabel 1 Search query settings

\begin{tabular}{llll}
\hline Sources & IEEE & Science Direct & Web of Science \\
\hline Years & $2013-2018$ & $2013-2018$ & $2013-2018$ \\
\hline Languange & English & English & English \\
\hline Run on & Full Text & Full Text & Full Text \\
\hline Subject areas & All Available & All Available & All Available \\
\hline $\begin{array}{l}\text { Date of } \\
\text { running search }\end{array}$ & $17 / 03 / 2018$ & $17 / 03 / 2018$ & $20 / 03 / 2018$ \\
\hline
\end{tabular}

171

\section{2.4. Criteria for Selected Articles}

173 Fig 1 shows the criteria for the selected article and all articles that meet the criteria are selected. Mapping of research space on feature extraction and cardiotocography classification becomes a general taxonomy and a rough overview of the four categories defined as initial targets. The division of this category is based on an intensive pre-survey of the selected literature resources. Any article that did not match the specified criteria as depicted in fig 1 was not selected. Criteria

178 that are not included are as follows: (1) Papers not written in English. (2) Focus on fetal heart rate and uterine contraction extraction and classification but with manual analysis features.

\subsection{The process of Collecting Articles}

181 In managing the list of articles, the author uses the Excel application which is composed of the

182 three databases used. The selected article is read in full by the authors and given several highlights 183 and important comments, and the taxonomy that has been set at the beginning is refined in the 184 classification of the articles in the listing. Each article is Summarize, tabulate, and all-important 185 findings are elaborated in detail. The word and excel application are used to store related 186 information such as lists of surveyed articles, source indexes, summary tables and descriptions, 187 objectives, review sources, audiences, data sets used, criteria of evaluation, techniques of 188 validation, etc. These data are presented in the supplementary materials as a comprehensive 189 indication of the obtained results. 
190 2.6. Article Statistics Information and Search Results Article

191 The taxonomy used to review these research articles that focus on automatic feature extraction and

192 cardiotocography classification is as depicted in fig. 2. This taxonomy stated the entire

193 development of various researches and modern applications. The classification stated four main

194 stages. The method proposed is discussed in the first stage (stage 1), this includes all proposed

195 method that presents steps and algorithms in the preprocessing stage, feature extraction and

196 classification and their use in cardiotocography (20/50 articles). Development of system for

197 automatic feature extraction along with cardiotocography classification is conducted in second

198 stage (stage 2) (7/50 articles). Next, the third stage (stage 3) comprised of reviews and survey

199 articles related to automatic feature extraction and cardiotocography classification (3/50 articles).

200 Finally, evaluation as well as comparative studies in determining the most optimum technique 201 related to extracting and classifying features and its comparisons is discussed in the last stage 202 (stage 4) (20/50 articles). 


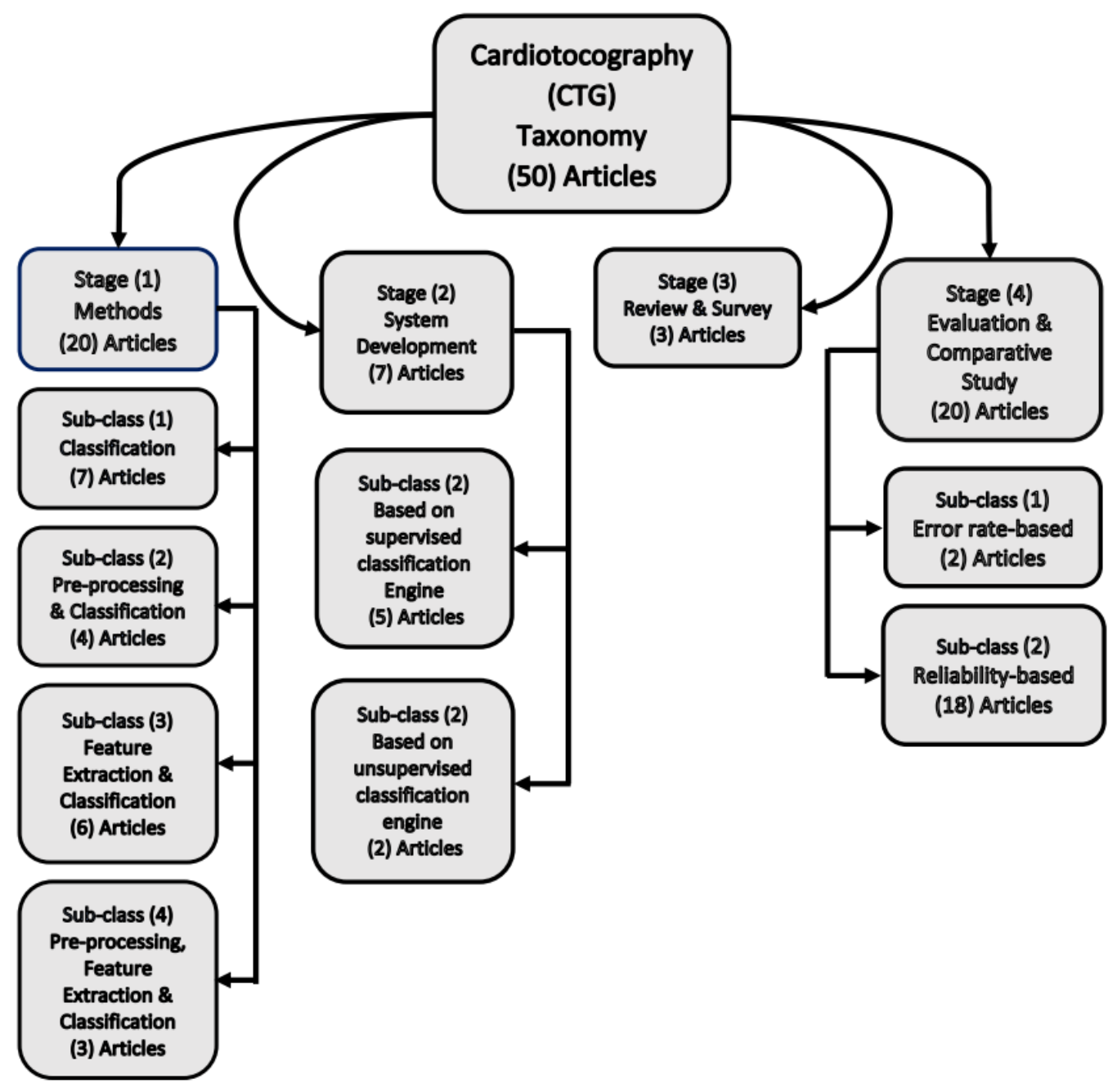

Fig. 2 The research literature taxonomy on automatic feature extraction and classification of cardiotocography

\section{3. METHODS}

207 As shown in Fig. 2, in this review the categorization of the CTG methodology is projected into 208 four stages.

\section{3.1. Techniques and algorithms}

210 This section discusses the methods and algorithms used in feature extraction and cardiotocography

211 classification of all articles that have been included in this study. The general context of articles in

212 this taxonomy is about achieving high performance or increasing the accuracy of

213 cardiotocography. This first stage has 20 articles out of 50 and it is divided as follows: 
214 - The first subclass $\{7 / 20$ articles $\}$ : focuses on the classification using the new proposed method 215 or modify conventional methods.

216 - The second subclass $\{4 / 20$ articles $\}$ : focuses on preprocessing and classification methods.

217 - The third subclass $\{6 / 20$ articles $\}$ : discusses feature extraction (features selection) and 218 classification methods.

219 - The fourth subclass $\{3 / 20$ articles $\}$ : discusses preprocessing, feature extraction and 220 classification methods.

221 As mentioned earlier, the first segmented group of articles discussed classification. Firstly, 222 Volterra based Neural Networks (VNN) using the Volterra series expansion are proposed in [6].

223 Secondly, the scattering transform is proposed in [20] as a new method for analyzing the variability 224 of FHR in the intrapartum period. Thirdly, The CTG trail using a 3-level classification presented 225 in [21] to classify CTG as Normal (N), Suspicious (S), and Pathological (P). Further, an ordinal 226 classification approach as used in [22] based on Binary Decomposition for prediction, that used 227 C.45 algorithm split the data and select a test that provided the best information gain, and used 228 Synthetic Minority Oversampling Technique (SMOTE). Next, [15] proposed a method that 229 implemented in the decision tree (DT) to analyze the CTG data to determine Fetal Distress. 230 Moreover, in clinical practice, the qualitative assessment of FHR records used fuzzy classification 231 with the Weighted Fuzzy Scoring System (WFSS) technique as proposed in [17]. Lastly, proposed 232 a scheme that is based on adaptive neuro-fuzzy inference systems (ANFIS) was trained to predict 233 the normal and the pathological state[19].

234 Next, the second segmented group discussed preprocessing and classification. Firstly, in [23] 235 Interpolate using Matlab implementation of Hermite Spline Interpolation proposed a classification 236 approach used for missing data, the technique is based on a latent class analysis method that seeks 237 to produce more objective labeling of training cases, and this is an important step in any 238 classification problem. Secondly, as proposed in [13] Principal Component Analysis (PCA) used 239 both as part of the one class classification process as well as for visualization, while Isomap, a 240 nonlinear dimensionality method, is used to confirm the visualization results of the PCA and in 241 this study, two simple one-class classifiers are tested: the nearest neighbor $(\mathrm{NN})$ and the Parzen 242 window classifier. Thirdly, preprocessing proposed in [12] used a moving average filter to 243 compensate for the noise and for contraction classification using K-Nearest Neighbor (KNN). 
244 Lastly, in preprocessing using Principal Component Analysis (PCA), the data utilized for training 245 and testing using the Adaptive Boosting algorithm (AdaBoost) to obtain strong groupings for 246 classifying unknown data and predict the state of the fetus proposed in [3].

247 Further, the third group discussed feature extraction and classification. Firstly, in[9], Shah et al. 248 proposed the use of correlation feature selection subset evaluation (CFS) with CFS calculated the correlation between features and classes for classification, Random Forest applied to classify data samples into classes and REPTree applied to produce decision trees, by calculating information acquisition using entropy and also using J48. Secondly, the K-means algorithm utilized to obtain the important features and for classification Support Vector Machine (SVM) was used as reported in [1]. Thirdly, as proposed in [16], the Genetic Algorithm (GA) implemented to minimize the number of features and determine the ideal subset of features and further classify fetuses using Support Vector Machine (SVM). Fourthly, feature extraction based on Genetic Algorithm (GA) used as proposed in [24] and as for classification linear regression, linear Support Vector Machine and kernel radial basis function (RBF) SVM were utilized. Moreover, as presented in [25], in order to identify the most important features, unsupervised swarm-based reduction techniques, hybrids of swarm intelligence and rough sets were employed and to check the level of errors generated from the reduce set by applying K-means clustering, and for classification, this study used single decision tree (DT), multilayer perceptron (MLP) neural network, probabilistic neural network (PNN) and random forest. Finally, as proposed in [26], it used fitMine as a new nonlinear dynamic model that reflected the relationship between signals of Fetal Heart Rate and Uterine Contraction by combining chaotic population model and unscented Kalman filter algorithm. In the last segmented group of articles, it discussed three components namely the preprocessing method, feature extraction, and classification. Firstly, as reported in [8] were used the principal component analysis (PCA) used as feature reduction, the correlation feature selection subset evaluation (CFS), CFS calculated the correlation between features and classes and three algorithms were used in this work: Random Forest, REPTree and the Linear Discriminant Analysis. Secondly, for preprocessing was used R-R intervals, while sequential feature selection algorithm was used to determine the informative subset of HRV features and Support Vector Machine was used to classify healthy fetuses and fetuses with adverse outcome presented in [27]. Lastly, [28] proposed 
274 enhanced and automated features (FI), Spectral Energy (SC) and Multiscale multifractal analysis

275 (SI) and for classification data Sparse Support Vector Machine (Sparse-SVM) was utilized.

276 3.2. System Development

277 This section discusses either a full-automatic or semi-automatic system that is used for feature

278 extraction and CTG classification for system development. This second stage has 7 articles out of

27950 and it is divided as follows:

280

281 - The first subclass $\{5 / 7$ articles $\}$ : based on supervised classification engine.

282 - The second subclass $\{2 / 7$ articles $\}$ : based on unsupervised classification engine.

283 The first subclass discusses the phase of the system. The following method is carried out in this 284 literature: Preprocessing, Segmentation and Identification in [29], Preprocessing, identification of 285 parameter, clinical validation, performances indexes estimation and statistical parameters in [30], 286 preprocessing, Identifying and classify in [31], Preprocessing and classification in [32], Feature 287 extraction and classification in [18]. In the second subclass, the related work focused on the 288 proposed system in [33] that used the weighted myriad filtering with identification and selection, 289 and in [4] agreement between the proposed technique and visual interpretation by obstetricians 290 was assessed using Bland-Altman analysis.

\section{3.3. Review/Survey}

292 The third Stage includes reviews and surveys aimed at describing cardiotocography, methods and 293 techniques used in feature extraction and cardiotocography classification. This third stage has 3 294 articles out of 50 and were found in [34], [14], [35]. The first in [34] presented Fetal HRV analysis 295 that provided distress information on fetal, combining HRV features calculated over the entire fetal 296 heart rate with contraction-dependent HRV features that improved the classification performance 297 during the second stage of labor. The second in [14], showed a review of human cardiotocography 298 interpretations and giving an opinion that machine learning can be used as a decision support 299 system by obstetricians and midwives and also can provide objective results in addition to using 300 normal practice. Finally as reported in [35], this study presented a comparison of the 301 cardiotocography classification system as outlined by the International Federation of Gynecology 302 and Obstetrics (FIGO) in 2015 and the UK National Institute for Health and Care Excellence 303 (NICE) in 2007 and 2014. 


\section{3.4. Evaluation and Comparative Study}

305 This section, the fourth stage, discusses the efforts to determine the best method for feature

306 extraction and cardiotocography classification by comparing methods based on several criteria.

307 This fourth stage has 20 articles out of 50.

308 The two classification schemes were compared that depended on one of the two subclasses:

309 - The error rate (stage 4/ subclass 1) shown in the articles [10], [36].

310 - The reliability criteria group (stage 4/ subclass 2 ) as reported in the articles [37], [38], [2], [7],

311 [39], [40], [41], [42], [43], [44], [45], [5], [46], [11], [47], [48], [49], [50].

312

313 One of the contributions to this work is to prioritize the latest articles in the research literature

314 using signal processing through content analysis from several major journals in the field of study.

315 The number of articles obtained from the literature is shown in Figure 3. These articles are (50)

316 articles selected based on predetermined criteria. As depicted in Figure 3, interest in the

317 development of methods and systems for feature extraction and cardiotocography classification

318 has increased accordingly over the rest.

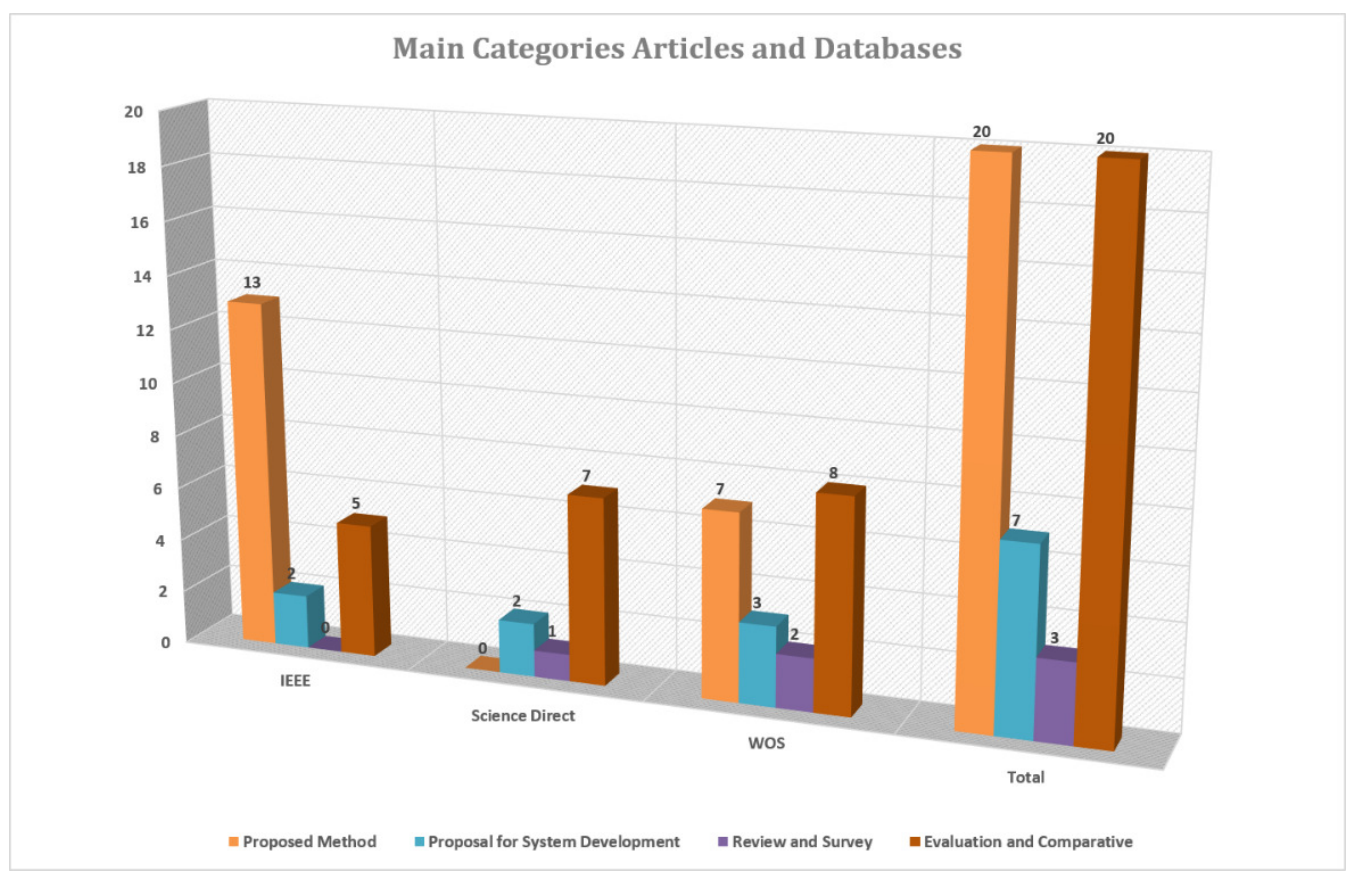


322 Fig 4 shows the number of articles based on each category and publication year. A total of 20 323 articles explained the proposed method in the study, proposals for system development totaling of 3247 articles, reviews and surveys totaling of 3 articles and evaluations and comparisons of two or 325 more methods amounted to 20 articles.

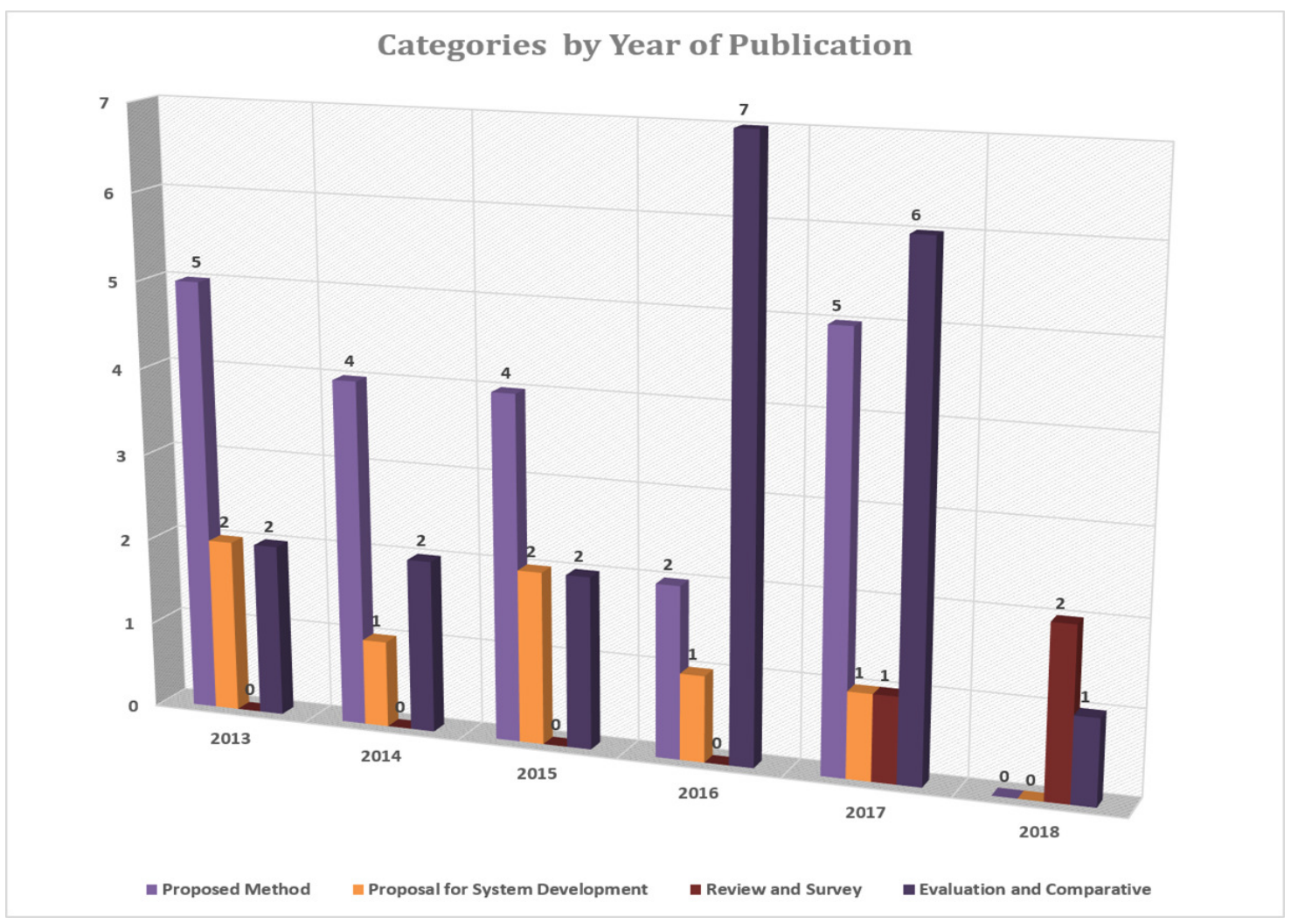

330 Fig 5 shows the author's affiliation country (the main author's country is considered in a case study 331 with several co-authors). Majority of the studies focused on feature extraction and 332 cardiotocography classification are in Italy, Turkey and India. Other countries include England, 333 the Czech Republic, Poland, Indonesia, Sweden, the Netherlands, Saudi Arabia, Portugal and 334 Romania. The number of co-authors was 145 out of 50 articles reviewed. Co-authors come from 335 various universities in the world with the majority coming from the fields of biomedical engineering, bioinformatics, signal processing, computer science, medicine, and pharmacy. 


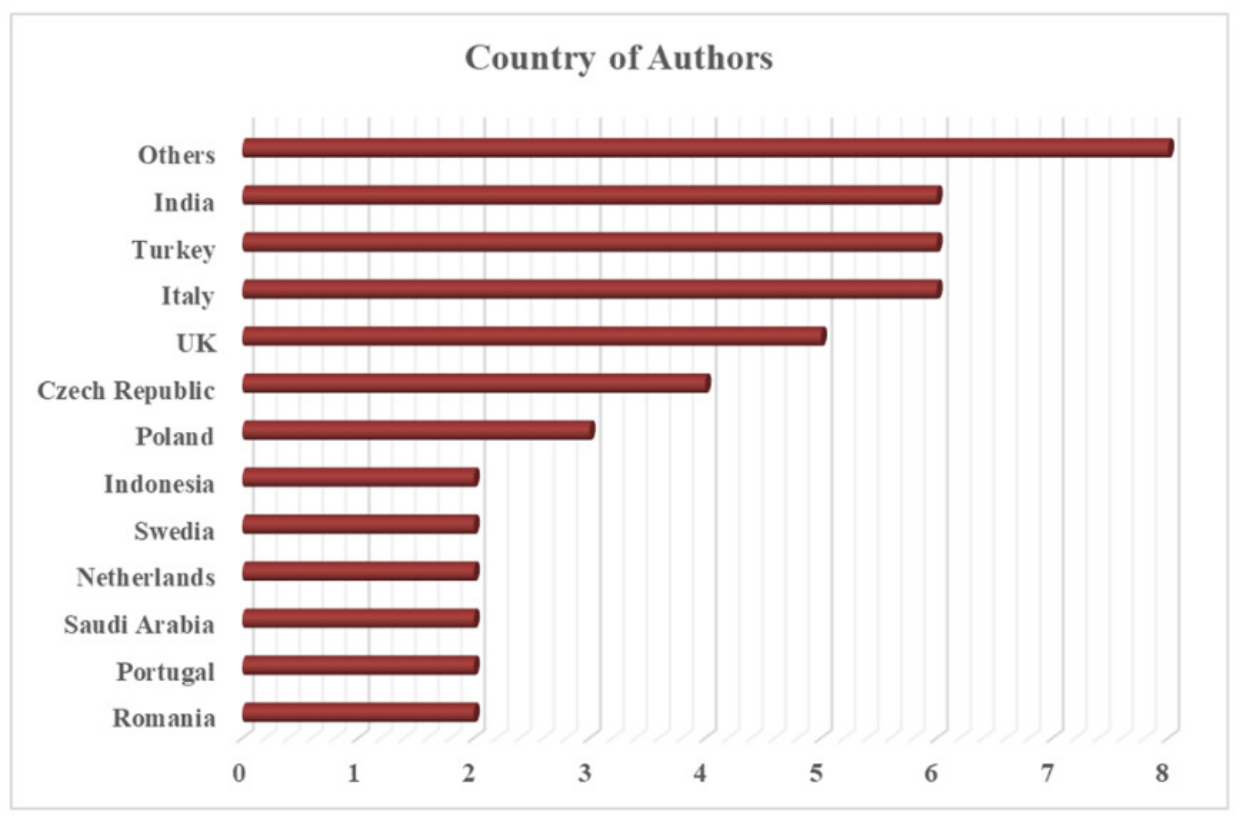

338

339

340

\section{4. DISCUSSION}

342 This study focused more on literature as compared to techniques or methods. This is the main 343 difference of this study in comparison to the other reviews. The literature was organized as a 344 proposed taxonomy. The taxonomy development of literature in a certain study area is helpful, 345 especially in an emerging research field. On the one hand, the taxonomy of literature can regulate 346 many publications, such as researchers can recognize the research developments and activities in 347 the field of the research area through research papers structuring. The comprehensive taxonomies 348 can describe the actual activities in the research area. Some articles can handle the introductory 349 aspects, while other articles can handle the problems of techniques and methods used now, and the 350 rest can contribute significantly to provide solutions in the field of research. Relevant taxonomic 351 literature can help organize various articles and research into manageable, coherent and 352 meaningful layouts Moreover, the order given by taxonomy gives the researchers useful 353 understandings into the topic in various aspects. First, explaining the main research areas and 354 subdirectories such as taxonomic examples on feature extraction and cardiotocography 355 classification in this study showed that researchers in the articles are more likely to suggest 356 methods for classification; so that, this research area can be considered as a promising path. This is also another important area is the development of feature extraction and classification for 
358

359

360

361

362

363

364

365

366

367

368

369

370

371

372

373

374

375

376

377

378

379

380

381

382

383

384

385

386

387

388

389

390

cardiotocography. Second, the taxonomy can reveal the gaps in the research area. Mapping the research on automatic techniques in extracting features and classification of cardiotocography into different classes can emphasize and highlight strength and limitation in the scope of each study. For example, the taxonomy proposed in this study showed interesting and prominent topics in terms of the methods proposed in previous studies, publication of surveys and evaluations and comparative studies. Furthermore, insights obtained from statistics on a single class of suggested taxonomies showed an active direction in feature extraction and cardiotocography classification to join the new research trends and strengthen the inactive research areas. Finally, the researchers who conduct a study in this area often recommend and adopt this taxonomy, promoting this taxonomic plan as a reference to assist in joint work and discussion with other researchers, such as articles in development, comparison of research and review of various automated methods that are not similar along with extraction feature techniques and cardiotocography classification. In this study too, research and identification of various types of datasets used in surveys are also conducted because identifying datasets used by previous studies was indeed vital. In addition, in this study also presents various important aspects of evaluation based on classification methods used. Further, a review of the various validation techniques and performance evaluation criteria adopted is conducted. Surveys conducted from the content of the literature reveal six aspects: (1) The description of the datasets used in the article, (2) The validation methods adopted, (3) The techniques used for the evaluation performance of the methods, (4) The motivation to use the automatic methods in detecting and classifying cardiotocography, (5) The challenges to success in using the method and (6) The recommendations for overcoming difficulties.

This research to shed light on cardiotocography researches, which provide valuable information for researchers and specialists in in gynecology and obstetrician clinics, in addition to the engineers working in the field of medical engineering and information technology. Where by collecting all data and studies in the field of cardiotocography and discussing its précised details and highlighting the problems, obstacles, motivation, challenges, recommendations and limitations of this research will gives a clear vision for those who are interested in this field, especially academic researchers.

\subsection{Datasets}

In this survey, there are 3 categories of datasets discussed: publicly available, private dataset and commercial dataset. In publicly dataset, researcher can download the datasets freely, in private dataset researcher need to request the private from infirmaries, university or research Centre and

Peer] Comput. Sci. reviewing PDF | (CS-2020:09:53118:1:1:NEW 10 Feb 2021) 
391 for commercial dataset it can be obtained from Clinical Environment. In our survey, we got 13

392 sources from UCI Machine Repository, CTU-UHB Database (University Hospital), Hospital

393 Femme Mere Enfant (HFME), CTU-UHB (Czech Technical University), Azienda Ospedaliera

394 Universitaria Federico II, Registration for CTG is recorded at a Neoventa STAN Molndal Sweden,

395 University Hospital of Bologna, Tertiary care University Hospital, Clinical Environment [36],

396 Clinical Environment[30], Careggi University Hospital of Florence, Mackay Memorial Hospital,

397 a tertiary referral center, and Maternity and Gynecological Clinic (University Hospital of Porto in

398 Portugal).

399 From our survey, UCI Machine Repository is the most widely used, secondly CTU-UHB database

400 from university hospital in Brno Czech Republic, thirdly CTU-UHB database from Czech

401 Technical University, and lastly Hospital Femme Mere Enfant (HFME). Four of these datasets are

402 publicly available in their website, so researchers can download the database freely. Table 2

403 summarizes the basic details of the cardiotocography dataset in the survey that we have conducted.

404 Table 2 Dataset used in reviewed research

\begin{tabular}{|c|c|c|c|c|}
\hline No. & Ref & Datasets & Type & Source \\
\hline 1 & $\begin{array}{l}{[8],[6],[13],[9],} \\
{[1],[37],[22],} \\
{[15],[2],[3],[7],} \\
{[16],[19],[47],} \\
{[48],[25],[49]}\end{array}$ & $\begin{array}{l}\text { Publicly } \\
\text { available }\end{array}$ & $\begin{array}{l}\text { Each record provides information } \\
\text { about morphological patterns } \\
\text { (physiological, suspect, } \\
\text { pathological) }\end{array}$ & $\begin{array}{l}\text { UCI Machine Repository } \\
\text { https://archive.ics.uci.edu/ml/dat } \\
\underline{\text { asets.html }}\end{array}$ \\
\hline 2 & $\begin{array}{l}{[23],[31],[37],} \\
{[12],[11],[26]} \\
{[29]}\end{array}$ & $\begin{array}{l}\text { Publicly } \\
\text { available }\end{array}$ & $\begin{array}{l}\text { Consisting of } 552 \text { records obtained } \\
\text { between } 2009 \text { and } 2012\end{array}$ & $\begin{array}{l}\text { CTU-UHB database } \\
\text { From the midwifery ward of the } \\
\text { university hospital in Brno, } \\
\text { Czech Republic } \\
\text { https://physionet.org/physiobank } \\
\text { database/ctu-uhb-ctgdb/ }\end{array}$ \\
\hline 3 & {$[20],[28]$,} & $\begin{array}{l}\text { Private } \\
\text { Datasets }\end{array}$ & $\begin{array}{l}\text { Intrapartum CTG has been routinely } \\
\text { monitored in HFME for the past } 30 \\
\text { years, with systematic monitoring } \\
\text { based on STAN }\end{array}$ & $\begin{array}{l}\text { Hospital Femme Mere Enfant } \\
\text { (HFME) (Lyon, France) } \\
\text { http://www.chu- } \\
\text { lyon.fr/en/hopital-femme-mere- } \\
\text { enfant }\end{array}$ \\
\hline 4 & {$[4],[21],[26]$} & $\begin{array}{l}\text { Publicly } \\
\text { Availabl } \\
\text { e }\end{array}$ & Normal and Pathological datasets & $\begin{array}{l}\text { CTU-UHB } \\
\text { From Czech Technical } \\
\text { University, Department of } \\
\text { Cybernatics } \\
\text { https://physionet.org/physiobank } \\
\text { database/ctu-uhb-ctgdb/ } \\
\end{array}$ \\
\hline 5 & {$[38]$} & $\begin{array}{l}\text { Private } \\
\text { Dataset }\end{array}$ & Normal fetuses and IUGRs & $\begin{array}{l}\text { Azienda Ospedaliera } \\
\text { Universitaria Federico II, } \\
\text { Napoli, Italy }\end{array}$ \\
\hline 6 & [27] & Private & 22 cases were included with adverse & Registration of CTG is \\
\hline
\end{tabular}




\begin{tabular}{|c|c|c|c|}
\hline & Dataset & $\begin{array}{l}\text { results, which was matched with } \\
110 \text { healthy cases }\end{array}$ & $\begin{array}{l}\text { recorded at Neoventa STAN } \\
\text { (Molndal, Sweden) }\end{array}$ \\
\hline [46] & $\begin{array}{l}\text { Private } \\
\text { Dataset }\end{array}$ & $\begin{array}{l}\text { Retrospective nesting case-control } \\
\text { studies including a series of } \\
\text { consecutive fetuses delivered with } \\
\text { metabolic acidemia in the second } \\
\text { stage of labor between } 2008 \text { and } \\
2013\end{array}$ & University Hospital of Bologna \\
\hline [39] & $\begin{array}{l}\text { Private } \\
\text { Dataset }\end{array}$ & $\begin{array}{l}100 \text { and } 51 \mathrm{CTG} \text { tracings were } \\
\text { consecutively selected from pre- } \\
\text { existing database of intrapartum } \\
\text { tracings. }\end{array}$ & $\begin{array}{l}\text { Tertiary care University } \\
\text { Hospital }\end{array}$ \\
\hline $\begin{array}{ll}9 & {[36]}\end{array}$ & $\begin{array}{l}\text { Commer } \\
\text { cial } \\
\text { Dataset }\end{array}$ & $\begin{array}{l}\text { Recorded from healthy pregnant } \\
\text { women }\end{array}$ & Clinical Environment [36] \\
\hline $10 \quad[30]$ & $\begin{array}{l}\text { Commer } \\
\text { cial } \\
\text { Dataset }\end{array}$ & $\begin{array}{l}\text { All CTGs are recorded during } \\
\text { routine daily fetal monitoring in the } \\
\text { clinical environment of women } \\
\text { between } 31 \text { and } 41 \text { weeks of } \\
\text { gestation both on antepartum and in } \\
\text { intrapartum }\end{array}$ & Clinical Environment [30] \\
\hline $11 \quad[40]$ & $\begin{array}{l}\text { Private } \\
\text { Dataset }\end{array}$ & $\begin{array}{l}\text { Ninety-seven traces of the FHR } \\
\text { were selected among those collected } \\
\text { between June and September } 2009\end{array}$ & $\begin{array}{l}\text { Careggi University Hospital of } \\
\text { Florence (Tuscany, Italy) }\end{array}$ \\
\hline $12 \quad[43]$ & $\begin{array}{l}\text { Private } \\
\text { Dataset }\end{array}$ & $\begin{array}{l}\text { Sixty-two CTG searches with } 20 \text { to } \\
30 \text {-minutes of sections collected } \\
\text { from different pregnant women at } \\
\text { the time of entry to the delivery } \\
\text { room for labor pain }\end{array}$ & $\begin{array}{l}\text { Mackay Memorial Hospital, a } \\
\text { tertiary referral center }\end{array}$ \\
\hline $13 \quad[44]$ & $\begin{array}{l}\text { Private } \\
\text { Dataset }\end{array}$ & $\begin{array}{l}\text { Datasets consists of } 2126 \\
\text { cardiotocograms }\end{array}$ & $\begin{array}{l}\text { Maternity and Gynecology } \\
\text { Clinic (Porto University } \\
\text { Hospital in Portugal) }\end{array}$ \\
\hline
\end{tabular}

\section{4.2. Techniques of Validation}

408 In analyzing general results, researchers evaluated independent datasets using techniques. In 409 addition, to evaluate the classification model proposed using validation techniques [48]. To 410 analyses the results of generalization, researchers evaluated an independent dataset by using a 411 technique. Basically, validation techniques are used when the aim of the study is to predict and 412 estimate the precision of a predictive model in practice [48]. Table 3 illustrates these validation 413 techniques used in the included articles of our survey.

\begin{tabular}{|l|l|l|}
\hline No & Name of Validation Technique & Reference \\
\hline
\end{tabular}




\begin{tabular}{|l|l|l|}
\hline 1 & $\begin{array}{l}\text { Cross Validation (10 fold cross validation, } \\
\text { k-fold cross validation and 2 fold stratified } \\
\text { cross validation) }\end{array}$ & $\begin{array}{l}{[23],[13],[9],[1],[12],[38],[27],[11],} \\
{[3],[32],[24],[47],[41],[26],[28],[22],} \\
{[7],[48],[49],[44]}\end{array}$ \\
\hline 2 & Confidence interval & {$[4]$} \\
\hline 3 & Paired sample t-test & {$[4],[46]$} \\
\hline 4 & Bland-Altman approach & {$[4]$} \\
\hline 5 & Mann - Whitney test & {$[46]$} \\
\hline 6 & Kappa Statistics & {$[39],[45],[40],[43]$} \\
\hline
\end{tabular}

417 In the table 3, there are 6 validation techniques used in this review. Firstly, Cross validation was

418 divided into 3 techniques, there are 10-fold cross validation, k-fold cross validation and 2-fold 419 cross validation, and note that cross validation are the most widely used in this review paper. Other

420 validation techniques are Kappa Statistics, Paired sample t-test, confidence interval, Bland-Altman 421 approach and Mann-Whitney test.

\section{4.3. Performance Measure}

423 The most common way to evaluate the used of various classifiers in our survey is the Evaluation using criteria. This method can assess the effectiveness of the classification methods. Classifier performance evaluation using various measurements such as confusion matrix, RMSE, selectivity, specificity, precision, accuracy, sensitivity, f-measure, quality index, gmean, MAE, AMAE, chisquare, spearman correlation, AUC, training time, testing time, misclassification error and confidence interval. Hence in this section all the above parameters are discussed. Table 4 shows the measurement criteria implemented in the reviewed articles.

\begin{tabular}{|l|l|l|l|l|l|l|l|l|}
\hline$\simeq$ & Reliability group & $\cup$ & $\infty$ & $\varangle$ & $\bullet$ & - & $\Sigma$ & $\cup$ \\
\hline
\end{tabular}




\begin{tabular}{|c|c|c|c|c|c|c|c|c|c|c|c|c|c|c|c|c|c|c|c|c|c|c|}
\hline \multirow[b]{2}{*}{$\stackrel{\Xi}{\Xi}$} & \multicolumn{4}{|c|}{ Confusion Matrix } & \multirow[b]{2}{*}{ 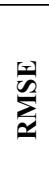 } & \multirow{2}{*}{ 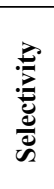 } & \multirow{2}{*}{ 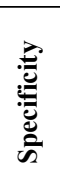 } & \multirow{2}{*}{ 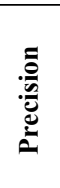 } & \multirow{2}{*}{ 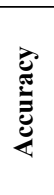 } & \multirow{2}{*}{ 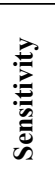 } & \multirow{2}{*}{ 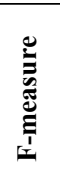 } & \multirow[b]{2}{*}{$\begin{array}{l}\stackrel{\vec{\theta}}{\bar{E}} \\
\stackrel{\Xi}{\Xi}\end{array}$} & \multirow[b]{2}{*}{ ت્ّ } & \multirow[b]{2}{*}{$\sum_{2}^{5}$} & \multirow[b]{2}{*}{$\sum_{4}^{5}$} & \multirow[b]{2}{*}{$=$} & \multirow[b]{2}{*}{$=0$} & \multirow[b]{2}{*}{ 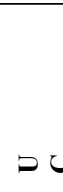 } & \multirow[b]{2}{*}{$=\sigma$} & & & \\
\hline & $\begin{array}{l}\stackrel{0}{0}^{\circ} \\
\hat{H}\end{array}$ & $\stackrel{\partial^{\circ}}{Z}$ & $\grave{\hat{Q}}_{\bar{I}}^{\circ}$ & $\grave{z}_{i}^{\circ}$ & & & & & & & & & & & & & & & & 0 o & $\cong 0$ & $0=4$ \\
\hline$[8]$ & $*$ & & & & & & & & $*$ & & & & & & & & & & & & & \\
\hline [6] & & & & & $*$ & & & & & & & & & & & & & & & & & \\
\hline$[23]$ & & & & & & & & & & & & & & & & $*$ & & & & & & \\
\hline$[31]$ & $*$ & $*$ & $*$ & $*$ & & $*$ & $*$ & & & & & & & & & & $*$ & & & & & \\
\hline [13] & & & & & & & & $*$ & & $*$ & & & & & & & & & & & & \\
\hline [9] & & & & & & & & $*$ & & $*$ & $*$ & & & & & & & & & & & \\
\hline [21] & & & & & & & & & $*$ & & & & & & & & & & & & & \\
\hline$[1]$ & & & & & & & & & $*$ & & & & & & & & & $*$ & & & & \\
\hline [37] & $*$ & $*$ & $*$ & $*$ & & $*$ & $*$ & & $*$ & $*$ & & & & & & & & & $*$ & $*$ & & \\
\hline$[12]$ & & & & & & & $*$ & & $*$ & $*$ & & & & & & & & & & & & \\
\hline$[38]$ & $*$ & $*$ & $*$ & $*$ & & & & & $*$ & & & & & & & & & & & & & \\
\hline$[27]$ & & & & & & & $*$ & & $*$ & $*$ & & & & & & & & & & & & \\
\hline$[11]$ & $*$ & $*$ & $*$ & $*$ & & & $*$ & & $*$ & $*$ & & $*$ & & & & & & & & & & \\
\hline$[22]$ & & & & & & & & & $*$ & & & & $*$ & $*$ & $*$ & & & & & & & \\
\hline$[10]$ & & & & & $*$ & & & & & & & & & $*$ & & & & & & & & \\
\hline$[15]$ & & & & & & & & & & & & & & & & & & & & & $*$ & \\
\hline$[2]$ & & & & & & & & & $*$ & & & & & & & & & & & & & \\
\hline$[3]$ & $*$ & $*$ & * & $*$ & & & * & $*$ & $*$ & $*$ & $*$ & $*$ & & & & & & $*$ & & & & \\
\hline [7] & $*$ & $*$ & $*$ & $*$ & & & $*$ & & $*$ & $*$ & $*$ & & & & & & & $*$ & & & & \\
\hline [46] & & & & & & & & & & & & & & & & & & $*$ & & & & $*$ \\
\hline [39] & & & & & & & & & $*$ & $*$ & & & & & & & & & & & & $*$ \\
\hline [36] & & & & & $*$ & & & & & & & & & & & & & & & & & \\
\hline [16] & & & & & & & & & $*$ & & & & & & & & & & & & & \\
\hline [32] & $*$ & $*$ & $*$ & $*$ & & & $*$ & & & $*$ & & & & & & & & & & & & \\
\hline$[40]$ & & & & & & & & & & & & & & & & & & & & & & $*$ \\
\hline [17] & $*$ & $*$ & $*$ & $*$ & & & $*$ & & $*$ & $*$ & & $*$ & & & & & & & & & & \\
\hline [19] & & & & & & & & & $*$ & & & & & & & & & & & & & \\
\hline [18] & & & & & & & & & & & & $*$ & & & & & & & & & & \\
\hline [47] & * & $*$ & $*$ & $*$ & & & & & $*$ & & & & & & & & & & & & & \\
\hline [41] & & & & & & & $*$ & & & $*$ & & & & & & & & & & & & \\
\hline [42] & & & & & & & $*$ & & & $*$ & & & & & & & & & & & & \\
\hline [26] & & & & & $*$ & & & & & & & & & & & & & & & & & \\
\hline [28] & & & & & & & $*$ & & & $*$ & & & & & & & & & & & & \\
\hline [48] & & & & & & & & * & $*$ & $*$ & $*$ & & & & & & & & & & & \\
\hline [25] & & & & & & & $*$ & & & $*$ & $*$ & & & & & & & & & & & \\
\hline [49] & & & & & & & & & & $*$ & $*$ & & & & & & & & & & & \\
\hline [44] & & & & & & & & $*$ & $*$ & $*$ & $*$ & & & & & & & & & & & \\
\hline Total & 10 & 9 & 9 & 9 & 4 & 2 & 13 & 5 & 19 & 18 & 7 & 4 & 1 & 2 & 1 & 1 & 1 & 4 & 1 & 1 & 1 & 3 \\
\hline$\%$ & 20 & 18 & 18 & 18 & 8 & 4 & 26 & 10 & 38 & 36 & 14 & 8 & 2 & 4 & 2 & 2 & 2 & 8 & 2 & 2 & 2 & 6 \\
\hline
\end{tabular}

437

438 Various studies on feature extraction and cardiotocography classification are as presented in table

4394 , as well as a full survey of different criteria and sub-criteria for the evaluation and benchmarking.

440 Moreover, to evaluate the cardiotocography classification method, the criteria used are confusion

441 matrix, RMSE, selectivity, specificity, precision, accuracy, sensitivity, f-measure, quality index,

442 gmean, MAE, AMAE, chi-square, spearman correlation, AUC, training time, testing time,

443 misclassification error and confidence interval. As clearly shown in Table 4, not all articles in this

444 scope of review utilized all the above-mentioned criteria- 


\section{4.4. Motivation}

446 From the articles that we reviewed, we found that researchers were motivated to develop and use

447 automated methods to diagnose, feature extraction and classification of cardiotocography focused

448 on improving early detection and rapid diagnosis, accuracy, guidelines, data sets, ONG experts,

449 methods and techniques. This section describes the benefits obtained from the literature, mapped

450 as benefits from the same group including quotations for each benefit for more discussion. A brief

451 summary of the motivation for the feature extraction and cardiotocography classification is shown

452 in figure 6.

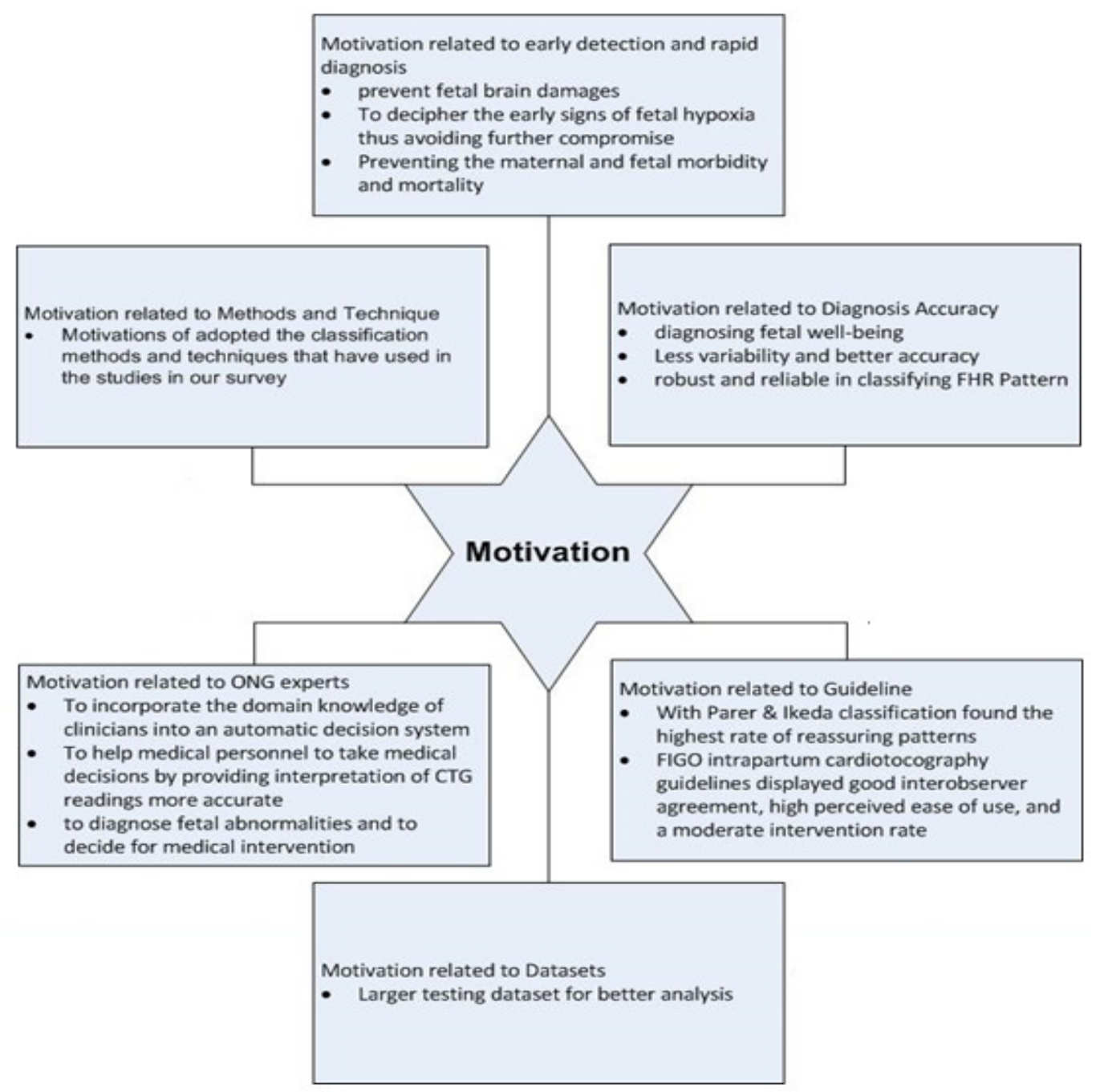




\subsubsection{Motivation related to early detection and rapid diagnosis}

458

459

460

461

462

463

464

465

466

467

468

469

470

471

472

473

474

475

476

477

478

479

480

481

482

483

484

485

486

In most cases oxygen insufficiency is normal, but the prolonged strain on the fetus for a longer period of period due to a week defense mechanism may lead to acidosis, as in [31] the best way to prevent fetal brain damages or even fetal morality is achieved by early detection of fetal oxygen insufficiency is crucial. In [4], automatic interpretation systems are needed to describe the initial signs of hypoxia so as to avoid further compromise. During the intrapartum period, fetal distress causes continuous fetal oxygen deficiency resulting in perinatal morbidity and mortality, [9] and [15] consistent monitoring and appropriate intervention are important to prevent maternal and fetal morbidity and mortality. CTG tracing computerized analysis is a major advance towards the solution to early identification of pre-natal pathology [38]. Early detection and prediction of pathological results can help reduce fetal morbidity and mortality worldwide as well as to prove whether the surgical intervention, such as cesarean section is needed as reported in [14]

\subsubsection{Motivation related to diagnosis accuracy}

Medical decision making relies heavily on automatic analysis of medical data, this greatly helps improve diagnosis and medical care [21]. Cardiotocography is widely used by doctors to obtain detailed physiological information from fetuses and pregnant women as a technique for diagnosing fetal well-being [3]. In article [14], automated computer analysis of cardiotocography signals showed strong evidence in diagnosing actual perinatal complications and predicted the onset of pathological results with far less variability and better accuracy. The advances in modern obstetric practice allowed many robust and reliable machine learning techniques to be utilized in classifying fetal heart rate signals [41].

\subsubsection{Motivation related to guidelines}

In the field of cardhotocography, there are many guidelines that show how to determine FHR and fetal general health condition. In this observation, RCOG, DFRMT and to a lesser extent, the SOGC and NICHD classifications showed greater caution in defining "normal" patterns. This can contribute to higher levels of intervention, which leads to an increased incidence of cesarean section. On the other hand, classification with Parer \& Ikeda found the highest level in the Reassuring pattern [40]. Additionally, the 2015 FIGO intrapartum cardiotocography guidelines 
487 displayed good interobserver agreement, ease of usage that is felt high and the level of intervention

488

489

490

491

492

493

494

495

496

497

498

499

500

501

502

503

Tabel 5 Number of different guidelines occurrence in the study

\begin{tabular}{|l|l|l|}
\hline No. & FHR guidelines Types & Reference \\
\hline 1 & $\begin{array}{l}\text { FIGO (International Federation of } \\
\text { Obstetrics and Gynecology) }\end{array}$ & $\begin{array}{l}{[2],[4],[11],[13],[14],[17],[18][20],} \\
{[50],[26],[28],[30],[33],[35],[39],[45],}\end{array}$ \\
\hline 2 & $\begin{array}{l}\text { NICHD (the National Institute of Child } \\
\text { Health Development) }\end{array}$ & $\begin{array}{l}{[4],[21],[30],[39],[40],[42],[45]} \\
\text { Care Excellence) }\end{array}$ \\
\hline 3 & $\begin{array}{l}\text { ACOG (the American College of } \\
\text { Obstetricians and Gynecologists) }\end{array}$ & {$[4],[21]$} \\
\hline 5 & $\begin{array}{l}\text { RCOG (the Royal College of } \\
\text { Obstetricians and Gynecologists) }\end{array}$ & {$[21],[46]$} \\
\hline 6 & $\begin{array}{l}\text { CNGOF (the French College of } \\
\text { Gynecology and Obstetrics) }\end{array}$ & {$[45]$} \\
\hline 7 & $\begin{array}{l}\text { NICHHD (the National Institute of Child } \\
\text { Health and Human Development) }\end{array}$ & {$[50]$} \\
\hline
\end{tabular}

\subsubsection{Motivation related to Datasets}

In this work [44], researchers used larger testing datasets for better analysis. The most important contribution of this research is the identification of significant features (only seven) upon feature selection process and further used for classification with classification accuracy comparable to original features.

\subsubsection{Motivation related to Obstetricians and Gynecologist (ONG) experts}

In order to overcome persistent inter and intra-observer variability, special research efforts are needed to incorporate physician domain knowledge into automatic decision systems [23]. In the work by [9] and [1], inconsistencies in visual evaluation can be eliminated by developing clinical decision support systems. Cardiotocography data is useful for obstetricians in diagnosing fetal 
504 abnormalities and can be used to decide on medical intervention before continuous damage to the

505 baby, but the interpretation of cardiotocography data carried out by obstetricians can never visually

506 be objective [7]. In this information era, the use of machine learning tools in medical diagnosis has

507 increased gradually. This is mainly because the effectiveness of classification and recognition

508 systems that have demonstrated able to improve in a great deal to help medical experts in 509 diagnosing diseases[49].

510 4.4.6. Motivation related to techniques and methods

511 in this section, the motivations of classifying techniques and methods implemented in the studies

512 of our survey will be presented. Table 6 tabulates the motivation to adopt cardiotocography 513 classification techniques and methods.

Table 6 Motivation to adopt cardiotocography classification techniques and methods

\begin{tabular}{|c|l|l|}
\hline & \multicolumn{1}{|c|}{$\begin{array}{c}\text { Methods \& } \\
\text { Techniques }\end{array}$} & \multicolumn{1}{c|}{ Motivation } \\
\hline 1 & Random Forest & $\begin{array}{l}\text { Random forest is widely used in statistical modeling techniques and } \\
\text { one of the most promising methods appears[8]. Random Forest has } \\
\text { managed to increase classification accuracy and accomplished } \\
\text { better generalization even for large databases in ensemble learning. }\end{array}$ \\
\hline 2 & $\begin{array}{l}\text { Volterra Neural } \\
\text { Network (VNN) }\end{array}$ & $\begin{array}{l}\text { VNN has fast and uniform convergence. Simulation has } \\
\text { demonstrated the efficiency of this techniques as proposed in } \\
\text { electronic fetal monitoring [6]. }\end{array}$ \\
\hline 3 & $\begin{array}{l}\text { A Novel } \\
\text { OAfw" "CTG- }\end{array}$ & $\begin{array}{l}\text { [38] has introduced a new software called CTG-OAS for a } \\
\text { comprehensive analysis of CTG signals in this study. This software } \\
\text { provides several tools for conducting reliable analysis. Also, } \\
\text { important procedures regarding machine learning, such as feature } \\
\text { extraction, pre-processing, classification and feature selection, are } \\
\text { inherent in the software. }\end{array}$ \\
\hline 4 & $\begin{array}{l}\text { Scattering } \\
\text { Transform }\end{array}$ & $\begin{array}{l}\text { Scattering transformation is proposed as a new tool for analyzing } \\
\text { the variability of intrapartum fetal heart rate (FHR). This consists } \\
\text { of a nonlinear extension of the underlying wavelet transformation, } \\
\text { thereby maintaining its multiscale nature [20]. }\end{array}$ \\
\hline 5 & $\begin{array}{l}\text { In this study, a bagging approach combined with three traditional } \\
\text { decision tree algorithms (random forest, Reduced Error Pruning } \\
\text { Tree (REPTree) and J48) has been applied to identify normal and } \\
\text { pathological fetal conditions using CTG data[20]. }\end{array}$ \\
\hline Approach & $\begin{array}{l}\text { SVM gives good accuracy [1] and has showed high performance } \\
\text { for binary classification with its ability to handle noisy data [2]. } \\
\text { SVM classification has become the most preferred techniques since } \\
\text { its introduction, and has been successfully used in many medical } \\
\text { decision support systems [16]. }\end{array}$ \\
\hline & Machine (SVM)
\end{tabular}




\begin{tabular}{|c|l|l|}
\hline 7 & $\begin{array}{l}\text { Artitifical Neural } \\
\text { Network (ANN) }\end{array}$ & $\begin{array}{l}\text { ANN is a practical tool to solve many complex nature signal } \\
\text { processing problems, such as curve installation, pattern recognition } \\
\text { and classification, grouping and analysis of dynamic time series } \\
\text { [37]. }\end{array}$ \\
\hline 8 & $\begin{array}{l}\text { Extreme } \\
\text { Learning } \\
\text { Machine (ELM) }\end{array}$ & $\begin{array}{l}\text { ELM tends to provide good generalization performance with fast } \\
\text { learning speed in many cases and can learn thousands of times } \\
\text { faster than conventional learning [37]. }\end{array}$ \\
\hline 10 & $\begin{array}{l}\text { K Nearest } \\
\text { Neighbor }\end{array}$ & $\begin{array}{l}\text { The classification method based on K Nearest Neighbor is } \\
\text { presented for automatic classification of various uterine } \\
\text { construction during labor [12]. K Nearest Neighbor is an example } \\
\text { of a classification method with parameter independence [7]. }\end{array}$ \\
\hline 11 & $\begin{array}{l}\text { Boosting } \\
\text { (AdaBoost) }\end{array}$ & $\begin{array}{l}\text { Typical ensemble learning algorithms, this study proposed new } \\
\text { design concepts and make great success in many different practical } \\
\text { applications [3]. }\end{array}$ \\
\hline System & $\begin{array}{l}\text { Sparse Support } \\
\text { Vector Machine } \\
\text { (Sparse-SVM) }\end{array}$ & $\begin{array}{l}\text { The possibility of assessing the efficient state of the fetus using the } \\
\text { proposed fuzzy inference method [17]. } \\
\text { achieve efficient fetal acidosis detection[28]. }\end{array}$ \\
\hline
\end{tabular}

515

516 The various methods and techniques used in cardiotocography classification are presented in table

517 6. Most of the articles surveyed in this study area expressed intention of achieving the best

518 accuracy level and highest performance from the classification model. The researcher sought to

519 increase the precision and the performance by offering a different classification or feature selection

520 method. In most studies, the results showed good performance and high accuracy of the

521 classification models based on the suggested method, showing that this area of research suggests

522 many effective methods for feature extraction and cardiotocography classification.

\section{4.5. Challenges}

524 Over the past few years, there has been an increase in the field of feature extraction and 525 cardiotocography classification, although there are still encounter difficulties and challenges in 526 numerous important respects. Various examples of these challenges are diagnosis, parameters, 527 guidelines, and many more. In table 7 presents details about reference challenges.

Tabel 7 Challenge categories of feature extraction and cardiotocography classification

\begin{tabular}{|l|lll} 
Challenge related to & $\bullet$ The REPTree algorithm has low accuracy especially in the accuracy
\end{tabular}




\begin{tabular}{|c|c|}
\hline algorithm & of suspected pathological status for small training sets. \\
\hline $\begin{array}{l}\text { Challenge related to } \\
\text { diagnosis }\end{array}$ & $\begin{array}{l}\text { - The knowledge and experience of the doctor largely influences } \\
\text { accuracy; } \\
\text { - Increasing cesarean delivery rates is one of the main reasons caused } \\
\text { by a lack of information provided by cardiotocography; } \\
\text { - The available evidence about the accuracy and efficacy of this } \\
\text { system is still limited. }\end{array}$ \\
\hline $\begin{array}{l}\text { Challenge related to } \\
\text { guidelines }\end{array}$ & $\begin{array}{l}\text { - In the guidelines there is still a lack of objective explanations for } \\
\text { some features of fetal heart rate; } \\
\text { - The existing guidelines have deficiencies in terms of uniformity and } \\
\text { uncertainty, therefore it is difficult to implement automatic systems; } \\
\text { - There is still a-lack of precision, leading to differences of opinion } \\
\text { among medical practitioners; } \\
\text { - FIGO results poor specificity; } \\
\text { - guidelines have not become more simple or more objective; } \\
\text { - Differ in the terminology used; } \\
\text { - NICHD system was rapidly criticized by some investigators; } \\
\text { - The usefulness of NICHD system is under debate; } \\
\text { - no evidence of NICHD effectiveness. }\end{array}$ \\
\hline $\begin{array}{l}\text { Challenge related to } \\
\text { features }\end{array}$ & $\begin{array}{l}\text { - Many different pattern in the gray zone; } \\
\text { - Baseline is the most basic feature of FHR; } \\
\text { - The missing value problem is another problem that needs to be } \\
\text { resolved; } \\
\text { - Features extracted from histogram data are less important; } \\
\text { - very difficult to assess; } \\
\text { - Complex FHR patterns are assessed with eyes that are prone to } \\
\text { - The complexity of patterns describing the FHR variability makes } \\
\text { the visual signal interpretation difficult and the accuracy of the } \\
\text { - The UA signal is often of poor quality. }\end{array}$ \\
\hline $\begin{array}{l}\text { Challenge related to } \\
\text { waveform }\end{array}$ & $\begin{array}{l}\text { - The FHR waveform has a complex form; } \\
\text { - The FHR waveform is a source of a lot of information, only a small } \\
\text { portion can be extracted by visual analysis; } \\
\text { - Heart rate signals often show complex and irregular fluctuations. }\end{array}$ \\
\hline $\begin{array}{l}\text { Challenge related to } \\
\text { dimensionality }\end{array}$ & $\begin{array}{l}\text { - The high dimension of CTG data are the problem for classification } \\
\text { computation; } \\
\text { - There is no guarantee that dimensions are higher and computing } \\
\text { time is greater; } \\
\text { - K-SVM reduces the feature dimension, however features of other } \\
\text { data with similar samples are not reduced. }\end{array}$ \\
\hline $\begin{array}{l}\text { Challenge related to } \\
\text { CTG interpretation }\end{array}$ & $\begin{array}{l}\text { - Increased birth by caesarean section and less specific in detecting } \\
\text { acidosis; } \\
\text { - Subjective interpretation and tedious technique; }\end{array}$ \\
\hline
\end{tabular}




\begin{tabular}{|c|c|}
\hline & $\begin{array}{l}\text { - Poor specificity, not always possible; } \\
\text { - Unnecessary intervention; } \\
\text { - Poor positive predictive value; } \\
\text { - no standardization in the interpretation of the information; } \\
\text { - because the fetus is in the womb, several measurement problems } \\
\text { arise; } \\
\text { - high complexity of signal patterns, which results in high levels of } \\
\text { intra and interobserver variability; } \\
\text { - CTG has not proven its benefits in neonatal death and morbidity; } \\
\text { - Conventional visual CTG interpretation is limited. }\end{array}$ \\
\hline $\begin{array}{l}\text { Challenge related to } \\
\text { classification }\end{array}$ & $\begin{array}{l}\text { - The FHR pattern classification still needs further improvement; } \\
\text { - Ignoring the suspect cases; } \\
\text { - Piquard classification was not applicable; } \\
\text { - The risk of a false classification of pathological cases remains high; } \\
\text { - The predictive capacity of the existing methods remains inaccurate; } \\
\text { - Traditional unsupervised methods provide very poor accuracy in } \\
\text { predicting different classes. }\end{array}$ \\
\hline $\begin{array}{l}\text { Challenge related to } \\
\text { time of diagnosis }\end{array}$ & $\begin{array}{l}\text { - Training time and test time takes longer; } \\
\text { - SVM consumes a lot of computational time }\end{array}$ \\
\hline $\begin{array}{l}\text { Challenge related to } \\
\text { ONG experts }\end{array}$ & $\begin{array}{l}\text { - Expertise is not always available, making CTG evaluation a difficult } \\
\text { task; } \\
\text { - Interpretation of CTG data after visual analysis performed by } \\
\text { obstetricians cannot be objective; } \\
\text { - the agreement between clinicians was moderate } \\
\text { - CTG recordings are analyzed by experts visually who make } \\
\text { subjective interpretations and cannot be reproduced. }\end{array}$ \\
\hline $\begin{array}{l}\text { Challenge related to } \\
\text { technical challege }\end{array}$ & $\begin{array}{l}\text { - The FHR record suffers from samples that are often invalid or lost, } \\
\text { due to sensor artifacts or error functions; } \\
\text { - great inter- and intra-observer variability; } \\
\text { - Lack of patients identification still occurs in } 8 \% \text { of antepartum } \\
\text { searches and } 31 \% \text { of intrapartum searches. }\end{array}$ \\
\hline $\begin{array}{l}\text { Challenge related to } \\
\text { dataset }\end{array}$ & $\begin{array}{l}\text { - Data interpretation ambiguity; } \\
\text { - Lack of late acceleration in the dataset; } \\
\text { - could not be objective and reproducible; } \\
\text { - Outlier value problem. }\end{array}$ \\
\hline $\begin{array}{l}\text { Challenge related to } \\
\text { evaluation }\end{array}$ & $\begin{array}{l}\text { - The classification uses a measure of performance evaluation, but it } \\
\text { is not enough to decide for a vital case especially in a medical } \\
\text { diagnosis; } \\
\text { - fetal hypoxia is only about } 30 \% \text { of the positive predictive value for } \\
\text { intrapartum cases; } \\
\text { - There has been a effective increase in surgical birth rate and } \\
\text { intrapartum cesarean section; } \\
\text { - The standard definition of FHR variability (FHRV) and agreement } \\
\text { on the methodology that will be used in its evaluation is still lacking; }\end{array}$ \\
\hline
\end{tabular}


- ANN is still not accepted as a valid tool

- One of the main disadvantages of Tocography is subjectivity in interpretation and has high frequency noise due to sudden movements during recording.

531

532 4.5.1. Challenges related to classification algorithm

533 In [8], Generally, the challenge related to classification algorithms like (The Random Forest, 534 Linear Discriminant Analysis (LDA) and REPTree) is based on the using of group classification.

535 One of the commonly used and most promising statistical modeling methods is the Random Forest.

536 The most important target is to reduce the error of the entire forest and the individual tree quality 537 is not important. The error of the random forest relies on the correlation between the two trees and 538 on the strength of the tree. The Random Forest evaluates which variables are essential in the 539 classification and runs effectively on big databases. The Linear Discriminant Analysis (LDA) is a 540 technique utilized for data classification. This method can catch the main difference between 541 classes, maximizes the ratio between-class variance to the within-class variance, and discount

542 irrelevant factors. The general purpose is to discover and analytically express boundary which 543 would most discriminate between the groups. REPTree as a fast decision tree learner represents a 544 set of machine learning algorithms for data mining and it has many tools like regression, clustering, 545 data preprocessing, classification, visualization, and association rules. This technique sorts values

546 for numeric attributes once and using reduced-error pruning. There are options available for the 547 REPTree. For the three-algorithm implemented to classify CTG, the REPTree algorithm has a low 548 accuracy mainly in the suspected pathological conditions for the small training sets compared to 549 the other two algorithms. Three algorithms were used such as Random Forest, Linear Discriminant 550 Analysis (LDA), and REPTree to classify CTG.

\subsubsection{Challenges related to diagnosis}

553 Explanation of information provided by CTG is not in accordance with any standards, the lack of

554 information provided by CTG is one of the main reasons for the increase in cesarean delivery [9].

555 In [50], computer analysis of fetal monitoring signals is proposed, but for now, available evidence 556 of the accuracy and efficacy of this system is still limited. In the traditional mode of CTG 
557 interpretation by visual analysis widely practiced and less time consuming, its accuracy depends

558 in large part on the knowledge and experience of the doctor [4].

559 4.5.3. Challenges related to guidelines

560 For the last 25 years the guidelines have not become more simpler or more objective, which could 561 guarantee their wide application[33]. Guidelines for interpretation have been proposed by several 562 different organizations in the terminology used [35], these guidelines are not only lack uniformity, 563 but also lack of objective explanation in some FHR features [4] and also uncertain, therefore, it is 564 difficult to implement in an automated system [21]. In addition, FIGO or NICHD guidelines are 565 based solely on experimental observations, they lack precision, poor specificity [20] lead to 566 differences of opinion among medical practitioners [21]. NICHD systems was rapidly criticized 567 by some investigators, the usefulness of NICHD system is under debate and still no evidence of 568 NICHD effectiveness [42].

\section{4.5.4. Challenges related to features}

570 In clinical practice, complicated FHR patterns are assessed visually (using eyes), which are prone 571 to error, inconsistent and unreliable [32], and many different pattern in gray zone [4]. Not only in 572 FHR pattern, the UA signal is often of poor quality [34]. Baseline is the most basic feature of the 573 FHR because all the other features are directly dependent on it [21]. In addition to the baseline, 574 the complexity of the patterns that describe FHR variability makes interpretation of visual signals 575 difficult and the accuracy of the analysis depends largely on the knowledge and experience of the 576 doctor [18]. Another drawback is the missing value problem and this that needs to be resolved [1]. 577 Based on ratings, features extracted from histogram data were less significant compared to features 578 extracted from the Fetal Heart Rate and readings of the Uterine Construction time series [2].

\subsubsection{Challenges related to waveform}

580 The FHR waveform is a source of numerous information, only a small portion can be extracted by 581 visual analysis [21], but the FHR waveform is complex [4]. In [27], Heart rate signals often showed 582 complex and irregular fluctuations that cannot be explained by spectral analysis.

\subsubsection{Dimensionality Challenges}

584 The high dimension relating to data input poses a problem in classification. If the dimensions are

585 high, the process of training machine learning will require large CPU time. But there is no 
586 guarantee that higher dimensions and greater computation time will also increase accuracy [1]. As

587 reported in [1], K-SVM reduced the feature dimension, but failed to reduce the data with the same 588 sample.

589

590

591

592

593

594

595

596

597

598

599

600

601

602

603

604

605

606

607

608

609

610

611

612

613

614

\subsubsection{Challenges related to CTG interpretation}

CTG has not proven yet its benefits in neonatal death and morbidity. This lack of benefits may reflect damage to the fetus during the procedure [35]. Conventional CTG visual interpretation is limited, and many previous studies have documented high intra-observer and inter-observer variations [43]. The main problem in interpreting the correct record is the high complexity of the signal pattern, which results in a high level of intra and inter observer variability [17], subjective interpretation and tedious technique[31]. EFM has a poor positive predictive value, while a high false positive rate is used to detect fetal hypoxia in the intrapartum period [11]. Besides that, the poor specificity of CTG leads to unnecessary interventions[27]. Moreover, since the fetus is in the womb, several measurement problems have arisen [36]. The consequence of various interpretations of CTG has increased cesarean delivery and less specific in detecting acidosis [1]. Also, there is no standardization in the interpretation of the information which was provided by CTG[15].

\subsubsection{Challenges related to classification}

Artificial Neural Networks, Fuzzy Systems, Genetic Algorithms and Supporting Vector Machines

for prediction of fetal conditions have been developed and tested, but these classifiers are only applied to normal and pathological cases, ignoring suspected cases.[2]. In four fetuses with piqued classification, acidemia could not be confirmed because the pattern of fetal heart rate (tachycardia, reduced to no variability or slow deceleration with normal baseline) is not included in one of the six categories [46]. The risk of false classification in pathological cases remains high in Indonesia [17]. Even few decades after the introduction of cardiotocography into clinical practice, the predictive capacity of the existing methods remains inaccurate[48]. Conversely, traditional grouping methods can identify normal CTG patterns, they are incapable of Suspicious and Pathological patterns, so, traditional unattended methods provide very poor accuracy in predicting different classes [49]. Although many obstetricians use CTG, the classification of the FHR pattern still needs further improvement [37]. 


\section{4.5.9. Challenges related to time of diagnosis}

616 Training time and testing time take longer and there is also no significant increase in the success

617 of network classification of more than 25 hidden layer sizes [37]. In [28], the SVM method

618 required very long running time. In addition, another challenge was due to ef lower classification

619 or prediction accuracy if data involved has complex characteristics such as noise, non-linearity, 620 non-stationery and others.

\section{4.5.10. Challenges related to ONG experts}

622 Interpretation of CTG data after visual analysis performed by obstetricians must be ascertain [7], 623 not based on subjective interpretation and cannot be reproduced [16]. When comparing 4 FHR 624 classification, our study indicates that the agreement between clinicians was moderate no matter 625 what are the proposed classification and even with a 5-tier system[45]. Besides that, Expertise is 626 not always available, making CTG evaluation a difficult task[22].

\section{4.5.11. Challenges related to technical matters}

628 The FHR record suffered from samples that are often invalid or lost, due to sensor artifacts or error 629 functions [10]. When CTG techniques are introduced into clinical practice, recordings are 630 interpreted by gynecologists and midwives through visual inspection, with clear consequences of 631 large inter-and intra-observer variability, which leads to unreliable conclusions about fetal 632 morbidity [3]. In [50], the lack of patients identification still occurs in $8 \%$ of antepartum searches 633 and $31 \%$ of intrapartum searches.

\section{4.5.12. Challenges related to datasets}

635 Interpretation of data through visual analysis performed by obstetricians cannot be objective and 636 can be reproduced [3]. In addition, the ambiguity of data interpretation also depends on the quality 637 of the data being measured [10]. The lack of late acceleration in the dataset is a big problem, 638 because slow acceleration followed by short-term variability is a high indicator of fetal acidosis 639 [2]. In addition, outlier value problems are other important problems that need to be solved. In [3], 640 we use datasets that do not has outlier values.

\section{4.5.13. Challenges related to evaluation}

642 As we know, classification uses performance measure for evaluation purpose, but it is still not 643 enough to decide for a vital case especially for medical diagnosis [7]. Although to predict fetal 
644 hypoxia during pregnancies, CTG was basically developed as a screening tool, the positive 645 predictive value for intrapartum fetal hypoxia is only about 30\% [5]. There has been a substantial 646 increase in operative vaginal delivery rates and intrapartum cesarean section [5]. Although it is 647 clinically important and widespread use of fetal monitoring, the standard definition of FHR 648 variability (FHRV) and agreement on the methodology to be used in its evaluation are lacking 649 [36]. ANN is still not accepted as a valid tool for classification purpose mainly because it is 650 difficult to explain how a diagnosis is achieved; since, ANN is considered as a nonlinear black box 651 [32]. On the other hand, one of the main disadvantages of Tocography is subjectivity in 652 interpretation and it has high frequency noise due to sudden movements during recording [12].

\section{4.6. Recommendation}

654 This section offers several important recommendations for literature specifically recommended 655 categories of cardiotocography classification and feature extraction as described in figure 7.

Recommendation for user

- Guidelines help practitioners

- Understand the physiology behind FHR

- Check the maternal pulse

- Understanding the types of intrapartum fetal hypoxia and fetal reserve

- Better accuracy
656

657

658
Accuracy Recommendation

- Preprocessing

- Feature extraction \& Feature Selection

- Carefully Evaluated

- Great care

- Larger Dataset

- Clinical information

- Different classification

- Classification universally standardized

Performance Recommendation

- Examine the classification performance over time

- Excluding some features

- Performance evaluation tools

- More practical

- Time-series information

- Machine learning technique

- Hybrid models

Fig. 7 Recommended categories of feature extraction and cardiotocography classification 
659 4.6.1. Recommendations to developers and researchers

660 Recommendations for developers and researchers offered in this section of the study and most

661 recommendations here are related to the performance and accuracy of feature extraction and 662 cardiotocography classification.

\section{4.6.1.1. Accuracy Recommendation}

664 From the articles reviewed, there is a possibility of increasing the classification accuracy through several recommendations. These recommendations are associated with accuracy that focuses on informative features, estimated parameters, and classification models.

667 CTG diagnosis accuracy depends on the analysis of characteristic FHRs and UCs [43]. FHR, 668 recorded either by ultrasound Doppler probe or by a scalp electrode, contains various artifacts, 669 therefore it is necessary to preprocess the FHR signal prior to feature extraction [23]. In [1], feature 670 extraction and selection is performed to obtain the hidden pattern of normal, irregular and 671 pathologic fetal state separately using K-Mean algorithm. The process of identification is based 672 four parameters (baseline, variability, acceleration and deceleration) and these need to be carefully 673 evaluated and extreme care is needed to interpret data at the boundaries region [21]. A larger 674 dataset and other classifiers are required to gain insight in which combination of HRV features is 675 the most informative[27]. Not only additional data is essential for parameter estimation, the 676 opinion of more physicians with varied level of experience is required too [21]. Additionally as 677 reported in this study, seven features (AC, DS, DP, ASTV, MSTV, ALTV and Mean) are 678 considered more appropriate for CTG data analysis [9]. To improve consistency in CTG practice, 679 classification systems must be universally standardized to enable the development and 680 dissemination of educational tools[35]. Besides that, inclusion of clinical information such as 681 gestational age or maternal temperature might also enhance the classification[27] and to avoid the 682 bias of interpretation, different classification techniques have been proposed[45]. Unclassifiable 683 CTG trace encountered during the second stage of labor should not be regarded simply as a 684 technical artefact but should always alert the clinician about an underlying fetal hypoxia and 685 prompt further testing to assess the fetal status more accurately including internal scalp monitoring 686 or fetal blood sampling[46]. 
687 4.6.1.2. Performance Recommendation

688 It is indeed vital to include more information during the process of labor especially the time-series 689 data, that should be considered to be integrated into the classifier for better performance. 690 Moreover, there are also additional clinical parameters that need to be investigated, such as 691 gestation, oxytocin augmentation, maternal infection, and many more [24]. Besides that, 692 examining the classification performance over time[27] and excluding some features to optimize 693 computational time and to achieve better performance[3], can also be done using performance 694 evaluation tools[7]. As reported in [21], width of the Confidence Interval suggested that more data 695 need to be included in the sample. As for the propose technique by Sundar et al., hybrid models 696 using statistical [49] and all machine learning techniques produced rather well performances, ANN 697 was shown superior to others[41]. As a future direction, neural networks can be used to tune the 698 parameters and to achieve better performance[25]. A fuzzy output of the fetal state with a 699 membership function over different periods of time can be suitable for a real-time clinical decision 700 support system[2].

701

702

703

704

705

706

707

708

709

710

711

712

713

714

715

716

\subsubsection{Recommendations to users}

Before starting any CTG recording, it is mandatory to check the maternal pulse to avoid erroneous recording of maternal heart rate as fetal[5]. gynecologists and clinicians need to distinguish the physiology behind FHR changes and then how to respond to them accordingly to each individual cases, instead of purely relying on guidelines for management[5]. Guidelines help practitioners, whose task is to interpret CTG traces, to understand different patterns of FHR in a more straightforward manner[11]. Clinicians must understand the types of intrapartum fetal hypoxia and fetal reserve is also vital to optimize outcomes[5], and clinicians must be able to provide better diagnosis of the problem because it is extremely important to avoid unnecessary interventions [45].

\section{LIMITATION}

There is some limitation from the literatures, for instance small sample size might mean the study was inadequately powered to make reliable extrapolations, inexistence of universally accepted guidelines. Some other limitations in this study include objective CTG definition that resulted in limited effectiveness of CTG monitoring, the use of cardiotocography for considerable intra and inter observer variability, low classification accuracy, improvement via hybrid models using statistical and machine learning techniques, failed to analyze the relationship between the FHR 
717 patterns and neonatal outcomes as well as not informing mothers to count fetal movements during

718 the intrapartum period and missing information on fetal movement.

\section{6. CONCLUSION}

720 As a conclusion, interpretation using cardiotocography is one of the most widely used methods in

721 Electronic Fetal Monitoring (EFM). Research in this field is still ongoing, even though the

722 description and relevant boundaries are still ambiguous. Hence it is crucial to gain understanding

723 and insight into this research. This systematic review aimed to contribute to the research area

724 through survey and classification of related research efforts. Research efforts in this study area are

725 categorized into four namely: proposed methods, system development, surveys and reviews

726 followed by evaluation and comparison of studies. Significant information was gathered by

727 intensive reading, summarizing and analyzing various previous studies specifically that are related

728 to, benefits and motivations, recommendations related to feature extraction and cardiotocography

729 classification as well as measurement of various performance along with diverse datasets that have

730 been used in previous researches. Further, challenges in this field of research have been identified

731 and recommendations to overcome as well as method to solve the limitations and drawbacks are

732 also provided. As compared to some other developing technologies; most studies aimed to focus

733 on the functional qualities of the technology and consider the non-functional aspects as lower

734 priorities. Users usutilize the technology that exists once the technology is made available.

735 Therefore, to ensure that this research is in line with the current technology, researchers must focus

736 on new technologies, such as the use of applications that can be employed using smartphones. To

737 the extent of our knowledge, research on feature extraction and cardiotocography classification

738 using smartphone-based applications has not been done, so this is an important research line that

739 are needed with the hope that it may intersect with several other technological scientific pathways.

\section{REFERENCES}

742 [1] N. Chamidah and I. Wasito, "Fetal state classification from cardiotocography based on feature extraction using hybrid K-Means and support vector machine," Advanced Computer Science and Information Systems (ICACSIS), 2015 International Conference on, 2015, pp. 37-41: IEEE.

[2] V. Nagendra, H. Gude, D. Sampath, S. Corns, and S. Long, "Evaluation of support vector machines and random forest classifiers in a real-time fetal monitoring system based on cardiotocography data," in Computational Intelligence in Bioinformatics and Computational Biology (CIBCB), 2017 IEEE Conference on, 2017, pp. 1-6: IEEE. 
750 [3] Y. Zhang and Z. Zhao, "Fetal State Assessment Based on Cardiotocography Parameters

751

752

753

754

755

756

757

758

759

760

761

762

763

764

765

766

767

768

769

770

771

772

773

774

775

776

777

778

779

780

781

782

783

784

785

786

787

788

789

790

791

792

793

794 Using PCA and AdaBoost," 2017.

[4] S. Das, K. Roy, and C. K. Saha, "A novel step towards machine diagnosis of fetal status in-utero: Calculation of baseline variability," in Research in Computational Intelligence and Communication Networks (ICRCICN), 2015 IEEE International Conference on, 2015, pp. 230-234: IEEE.

[5] A. Pinas and E. Chandraharan, "Continuous cardiotocography during labour: Analysis, classification and management," Best practice \& research Clinical obstetrics \& gynaecology, vol. 30, pp. 33-47, 2016.

[6] T. I. Haweel and J. I. Bangash, "Volterra neural analysis of fetal cardiotocographic signals," in Communications, Signal Processing, and their Applications (ICCSPA), 2013 1st International Conference on, 2013, pp. 1-5: IEEE.

[7] H. Sahin and A. Subasi, "Classification of the cardiotocogram data for anticipation of fetal risks using machine learning techniques," Applied Soft Computing, vol. 33, pp. 231-238, 2015.

[8] P. Tomas, J. Krohova, P. Dohnalek, and P. Gajdos, "Classification of cardiotocography records by random forest," in Telecommunications and Signal Processing (TSP), 2013 36th International Conference on, 2013, pp. 620-923: IEEE.

[9] S. A. A. Shah, W. Aziz, M. Arif, and M. S. A. Nadeem, "Decision trees based classification of cardiotocograms using bagging approach," in Frontiers of Information Technology (FIT), 2015 13th International Conference on, 2015, pp. 12-17: IEEE.

[10] G. Frigo and G. Giorgi, "Comparative evaluation of on-line missing data regression techniques in intrapartum FHR measurements," in Instrumentation and Measurement Technology Conference (I2MTC), 2017 IEEE International, 2017, pp. 1-6: IEEE.

[11] Z. Cömert and A. F. Kocamaz, "A novel software for comprehensive analysis of cardiotocography signals "CTG-OAS"," in Artificial Intelligence and Data Processing Symposium (IDAP), 2017 International, 2017, pp. 1-6: IEEE.

[12] R. Jyothi, S. Hiwale, and P. V. Bhat, "Classification of labour contractions using KNN classifier," in Systems in Medicine and Biology (ICSMB), 2016 International Conference on, 2016, pp. 110-113: IEEE.

[13] D. Gavrilis, G. Nikolakopoulos, and G. Georgoulas, "A one-class approach to cardiotocogram assessment," in Engineering in Medicine and Biology Society (EMBC), 2015 37th Annual International Conference of the IEEE, 2015, pp. 518-521: IEEE.

[14] P. Fergus, M. Selvaraj, and C. Chalmers, "Machine learning ensemble modelling to classify caesarean section and vaginal delivery types using Cardiotocography traces," Computers in biology and medicine, vol. 93, pp. 7-16, 2018.

[15] A. E. Permanasari and A. Nurlayli, "Decision tree to analyze the cardiotocogram data for fetal distress determination," in Sustainable Information Engineering and Technology (SIET), 2017 International Conference on, 2017, pp. 459-463: IEEE.

[16] H. Ocak, "A medical decision support system based on support vector machines and the genetic algorithm for the evaluation of fetal well-being," Journal of medical systems, vol. 37, no. 2, p. 9913, 2013.

[17] R. Czabański, J. Jeżewski, K. Horoba, and M. Jeżewski, "Fetal state assessment using fuzzy analysis of fetal heart rate signals-Agreement with the neonatal outcome," Biocybernetics and Biomedical Engineering, vol. 33, no. 3, pp. 145-155, 2013. 
795

796

797

798

799

800

801

802

803

804

805

806

807

808

809

810

811

812

813

814

815

816

817

818

819

820

821

822

823

824

825

826

827

828

829

830

831

832

833

834

835

836

837

838

839

840

[18] R. Czabanski, J. Wrobel, J. Jezewski, J. Leski, and M. Jezewski, "Efficient evaluation of fetal wellbeing during pregnancy using methods based on statistical learning principles," Journal of Medical Imaging and Health Informatics, vol. 5, no. 6, pp. 1327-1336, 2015.

[19] H. Ocak and H. M. Ertunc, "Prediction of fetal state from the cardiotocogram recordings using adaptive neuro-fuzzy inference systems," Neural Computing and Applications, vol. 23, no. 6, pp. 1583-1589, 2013.

[20] V. Chudáček, J. Andén, S. Mallat, P. Abry, and M. Doret, "Scattering transform for intrapartum fetal heart rate variability fractal analysis: a case-control study," IEEE Transactions on Biomedical Engineering, vol. 61, no. 4, pp. 1100-1108, 2014.

[21] S. Das, K. Roy, and C. Saha, "Determination of window size for baseline estimation of fetal heart rate using CTG," in Computer, Communication, Control and Information Technology (C3IT), 2015 Third International Conference on, 2015, pp. 1-5: IEEE.

[22] G. Georgoulas, P. Karvelis, D. Gavrilis, C. D. Stylios, and G. Nikolakopoulos, "An ordinal classification approach for CTG categorization," in Engineering in Medicine and Biology Society (EMBC), 2017 39th Annual International Conference of the IEEE, 2017, pp. 26422645: IEEE.

[23] G. Georgoulas, J. Spilka, P. Karvelis, V. Chudáček, C. Stylios, and L. Lhotská, "A three class treatment of the FHR classification problem using latent class analysis labeling," in Engineering in Medicine and Biology Society (EMBC), 2014 36th Annual International Conference of the IEEE, 2014, pp. 46-49: IEEE.

[24] L. Xu, C. W. Redman, S. J. Payne, and A. Georgieva, "Feature selection using genetic algorithms for fetal heart rate analysis," Physiological measurement, vol. 35, no. 7, p. 1357, 2014.

[25] H. H. Inbarani, P. N. Banu, and A. T. Azar, "Feature selection using swarm-based relative reduct technique for fetal heart rate," Neural Computing and Applications, vol. 25, no. 34, pp. 793-806, 2014.

[26] S.-H. Kim, H.-J. Yang, and S.-W. Lee, "FitMine: automatic mining for time-evolving signals of cardiotocography monitoring," Data Mining and Knowledge Discovery, vol. 31, no. 4, pp. 909-933, 2017.

[27] G. J. Warmerdam, R. Vullings, J. O. Van Laar, J. Bergmans, L. Schmitt, and S. Oei, "Selective heart rate variability analysis to account for uterine activity during labor and improve classification of fetal distress," in Engineering in Medicine and Biology Society (EMBC), 2016 IEEE 38th Annual International Conference of the, 2016, pp. 2950-2953: IEEE.

[28] J. Spilka, J. Frecon, R. Leonarduzzi, N. Pustelnik, P. Abry, and M. Doret, "Sparse support vector machine for intrapartum fetal heart rate classification," IEEE journal of biomedical and health informatics, vol. 21, no. 3, pp. 664-671, 2017.

[29] A. Pasarica, D. Nemescu, H. Costin, and C. Rotariu, "AUTOMATIC ANALYSIS OF CARDIOTOCOGRAPHIC RECORDINGS FOR FETAL ACIDOSIS STUDY," MEDICAL-SURGICAL JOURNAL-REVISTA MEDICO-CHIRURGICALA, vol. 121, no. 1, pp. 206-214, 2017.

[30] M. Romano, P. Bifulco, M. Ruffo, G. Improta, F. Clemente, and M. Cesarelli, "Software for computerised analysis of cardiotocographic traces," Computer methods and programs in biomedicine, vol. 124, pp. 121-137, 2016.

[31] C. Rotariu, A. Pasarica, G. Andruseac, H. Costin, and D. Nemescu, "Automatic analysis of the fetal heart rate variability and uterine contractions," in Electrical and Power 
841

842

843

844

845

846

847

848

849

850

851

852

853

854

855

856

857

858

859

860

861

862

863

864

865

866

867

868

869

870

871

872

873

874

875

876

877

878

879

880

881

882

883

884
Engineering (EPE), 2014 International Conference and Exposition on, 2014, pp. 553-556: IEEE.

[32] A. Georgieva, S. J. Payne, M. Moulden, and C. W. Redman, "Artificial neural networks applied to fetal monitoring in labour," Neural Computing and Applications, vol. 22, no. 1, pp. 85-93, 2013.

[33] J. Wróbel, K. Horoba, T. Pander, J. Jeżewski, and R. Czabański, "Improving fetal heart rate signal interpretation by application of myriad filtering," Biocybernetics and Biomedical Engineering, vol. 33, no. 4, pp. 211-221, 2013.

[34] G. J. Warmerdam et al., "Detection rate of fetal distress using contraction-dependent fetal heart rate variability analysis," Physiological measurement, 2018.

[35] M. Bhatia, K. R. Mahtani, D. Nunan, and A. Reddy, "A cross-sectional comparison of three guidelines for intrapartum cardiotocography," International Journal of Gynecology \& Obstetrics, vol. 138, no. 1, pp. 89-93, 2017.

[36] M. Romano, P. Bifulco, A. Ponsiglione, G. Gargiulo, F. Amato, and M. Cesarelli, "Evaluation of floatingline and foetal heart rate variability," Biomedical Signal Processing and Control, vol. 39, pp. 185-196, 2018.

[37] Z. Cömert, A. F. Kocamaz, and S. Güngör, "Cardiotocography signals with artificial neural network and extreme learning machine," in Signal Processing and Communication Application Conference (SIU), 2016 24th, 2016, pp. 1493-1496: IEEE.

[38] G. Magenes, R. Bellazzi, A. Malovini, and M. G. Signorini, "Comparison of data mining techniques applied to fetal heart rate parameters for the early identification of IUGR fetuses," in Engineering in Medicine and Biology Society (EMBC), 2016 IEEE 38th Annual International Conference of the, 2016, pp. 916-919: IEEE.

[39] M. Rei et al., "Interobserver agreement in CTG interpretation using the 2015 FIGO guidelines for intrapartum fetal monitoring," European Journal of Obstetrics and Gynecology and Reproductive Biology, vol. 205, pp. 27-31, 2016.

[40] M. Di Tommaso, V. Seravalli, A. Cordisco, G. Consorti, F. Mecacci, and F. Rizzello, "Comparison of five classification systems for interpreting electronic fetal monitoring in predicting neonatal status at birth," The Journal of Maternal-Fetal \& Neonatal Medicine, vol. 26, no. 5, pp. 487-490, 2013.

[41] Z. Cömert and A. Kocamaz, "Comparison of Machine Learning Techniques for Fetal Heart Rate Classification," Acta Physica Polonica A, vol. 132, no. 3, pp. 451-454, 2017.

[42] S. M. Gamboa, O. R. Giménez, J. P. Mancho, M. L. Moros, J. R. Sada, and S. C. Mateo, "Diagnostic accuracy of the FIGO and the 5-tier fetal heart rate classification systems in the detection of neonatal acidemia," American journal of perinatology, vol. 34, no. 05, pp. 508-514, 2017.

[43] C.-Y. Chen, C. Yu, C.-C. Chang, and C.-W. Lin, "Comparison of a novel computerized analysis program and visual interpretation of cardiotocography," PloS one, vol. 9, no. 12, p. e112296, 2014.

[44] M. Arif, "Classification of cardiotocograms using random forest classifier and selection of important features from cardiotocogram signal," Biomaterials and Biomechanics in Bioengineering, vol. 2, no. 3, pp. 173-183, 2015.

[45] C. Garabedian et al., "Inter-observer reliability of 4 fetal heart rate classifications," Journal of gynecology obstetrics and human reproduction, vol. 46, no. 2, pp. 131-135, 2017. 
885 [46] T. Ghi et al., "Cardiotocographic findings in the second stage of labor among fetuses delivered with acidemia: a comparison of two classification systems," European Journal of Obstetrics and Gynecology and Reproductive Biology, vol. 203, pp. 297-302, 2016.

[47] E. Y1lmaz, "Fetal State Assessment from Cardiotocogram Data Using Artificial Neural Networks," Journal of Medical and Biological Engineering, vol. 36, no. 6, pp. 820-832, 2016.

[48] S. Chinnasamy, C. Muthusamy, and G. Gopal, "An Outlier Based Bi-Level Neural Network Classification System for Improved Classification of Cardiotocogram Data," Life Science Journal, vol. 10, no. 1, pp. 244-251, 2013.

[49] C. Sundar, M. Chitradevi, and G. Geetharamani, "Incapable of identifying suspicious records in CTG data using ANN based machine learning techniques," 2014.

[50] I. Nunes and D. Ayres-de-Campos, "Computer analysis of foetal monitoring signals," Best Practice \& Research Clinical Obstetrics \& Gynaecology, vol. 30, pp. 68-78, 2016. 
Figure 1

Article selection, search query and inclusion criteria 


\section{Query}

(Cardiotocogram OR Cardiotocograph OR Cardiotocography) AND ("fetal heart rate" OR baseline OR "baseline variability" OR acceleration OR deceleration OR "uterine contraction") AND ("FHR-monitoring" OR "feature extraction" OR classification OR diagnoses)

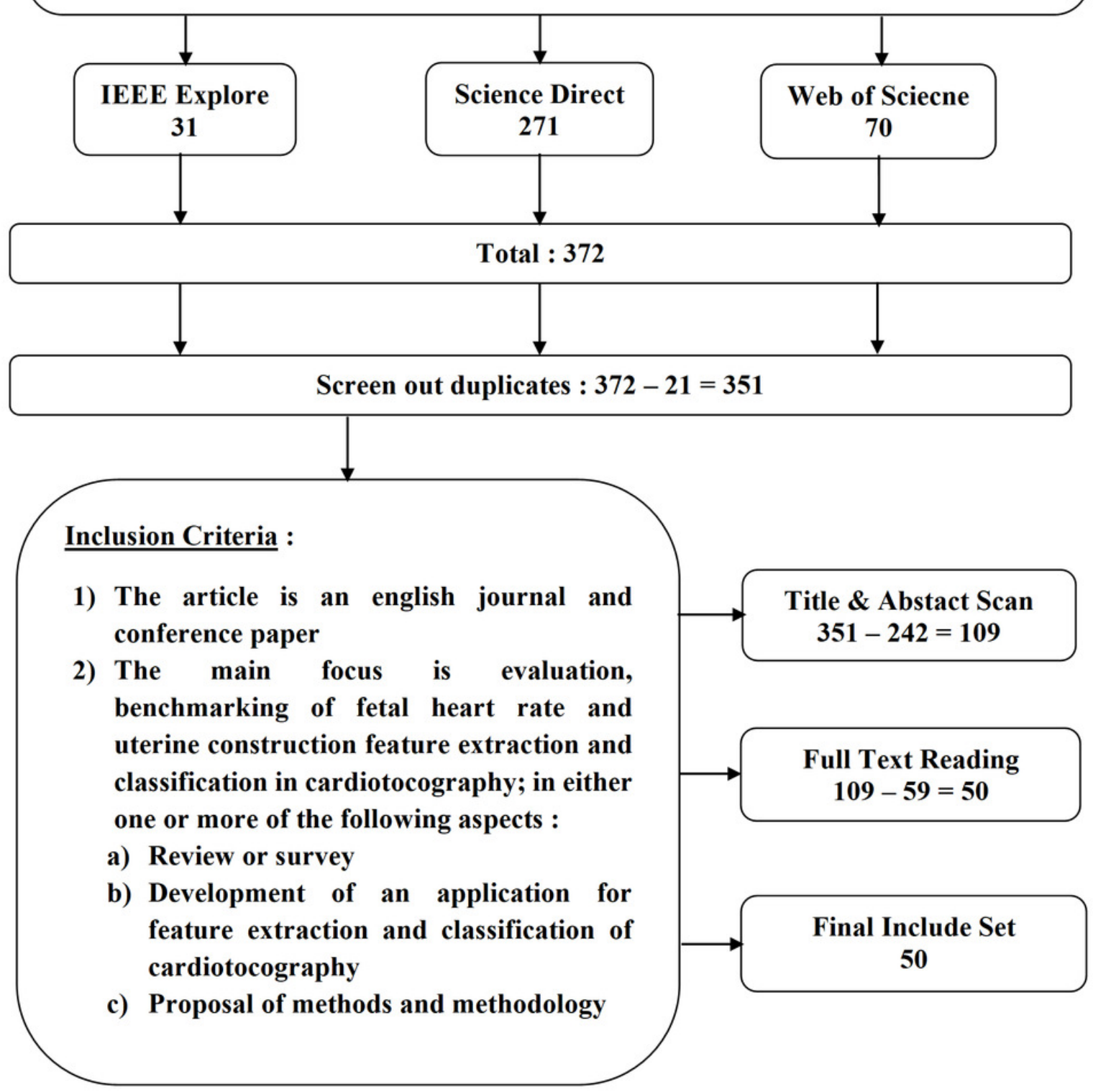


Figure 2

The research literature taxonomy on automatic feature extraction and classification of cardiotocography

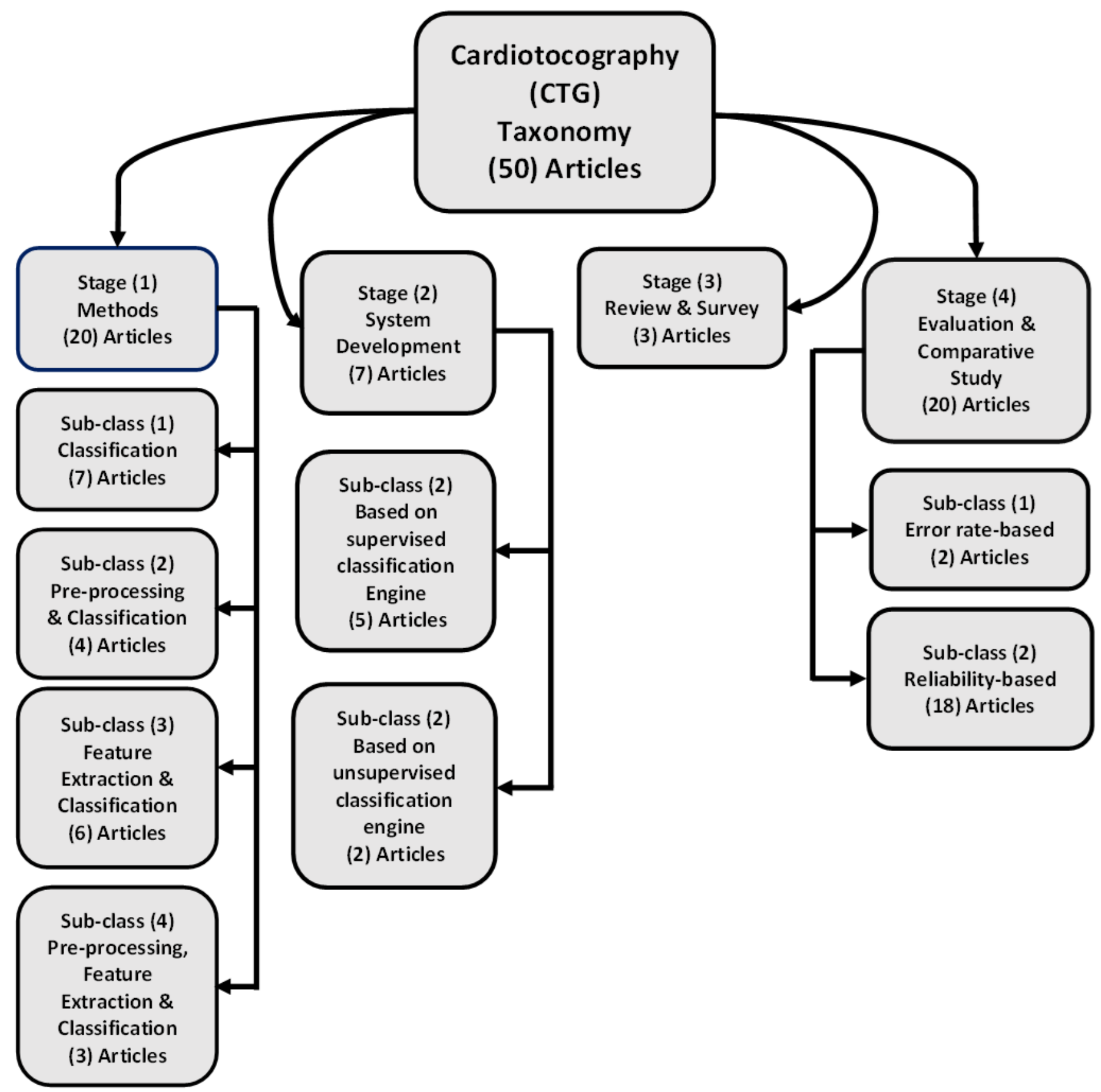




\section{Figure 3}

Articles number based on main categories and the database

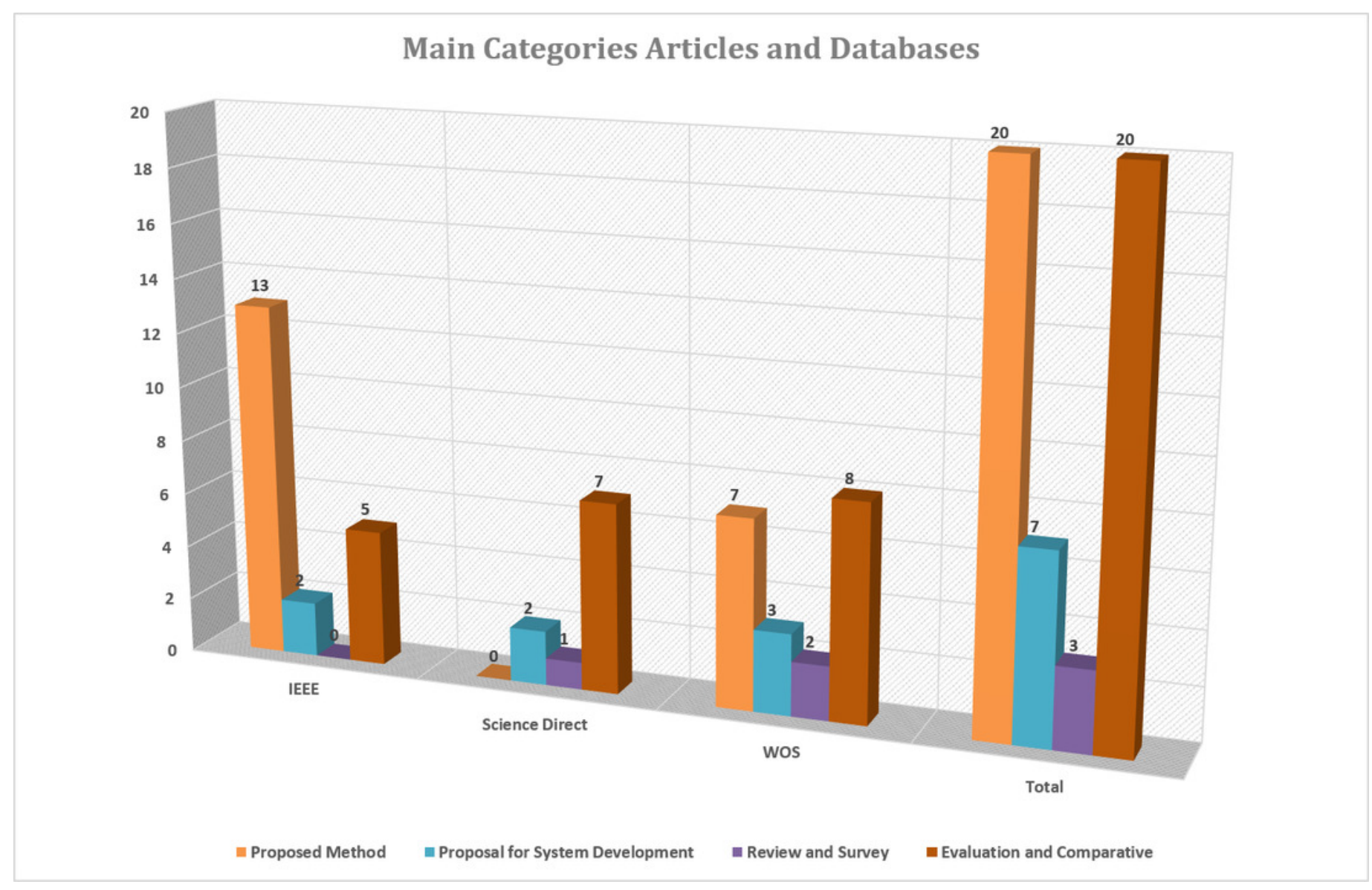


Figure 4

The number of articles in each category based on the year of publication

\section{Categories by Year of Publication}

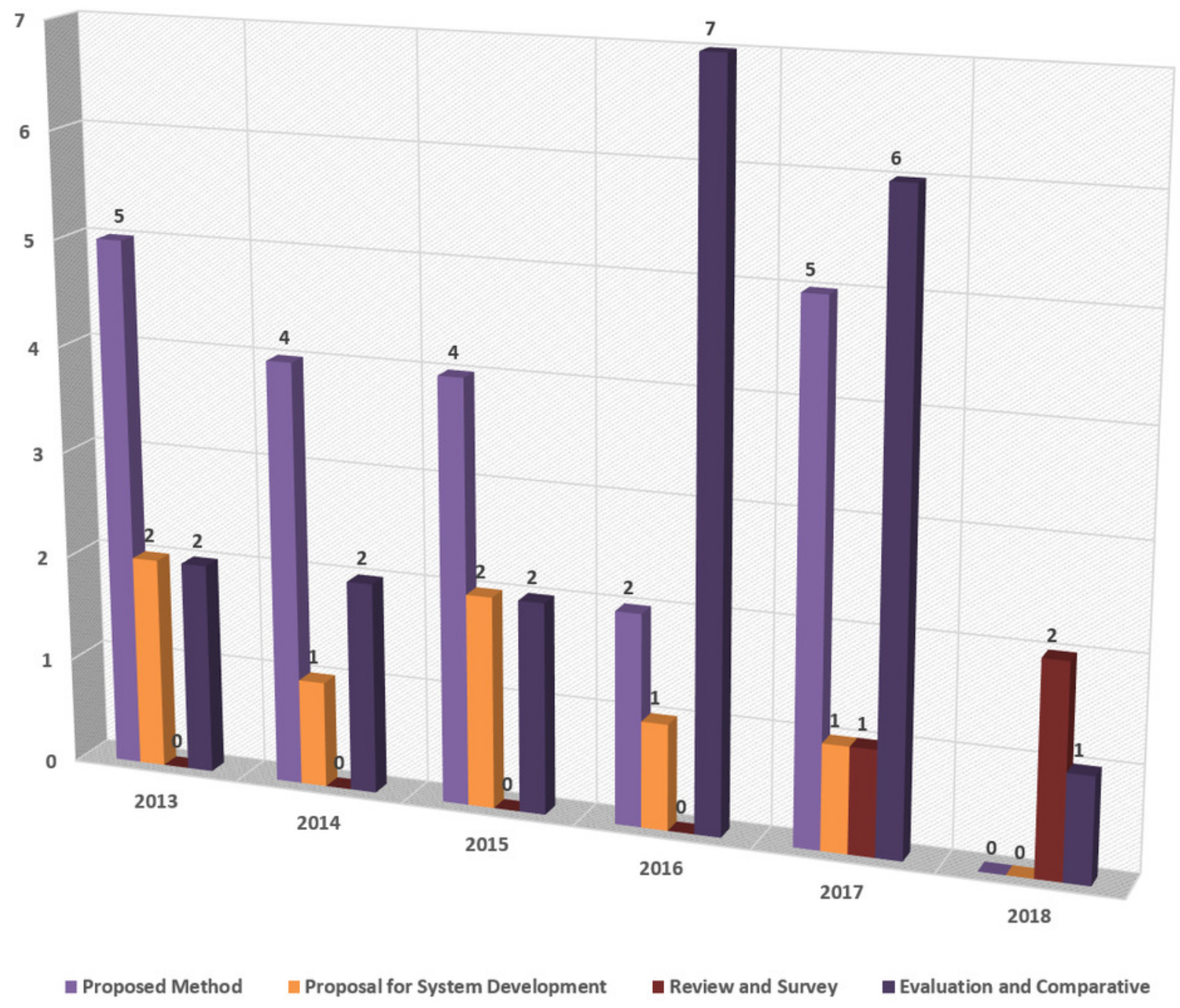


Figure 5

Articles number based on the author's affiliation

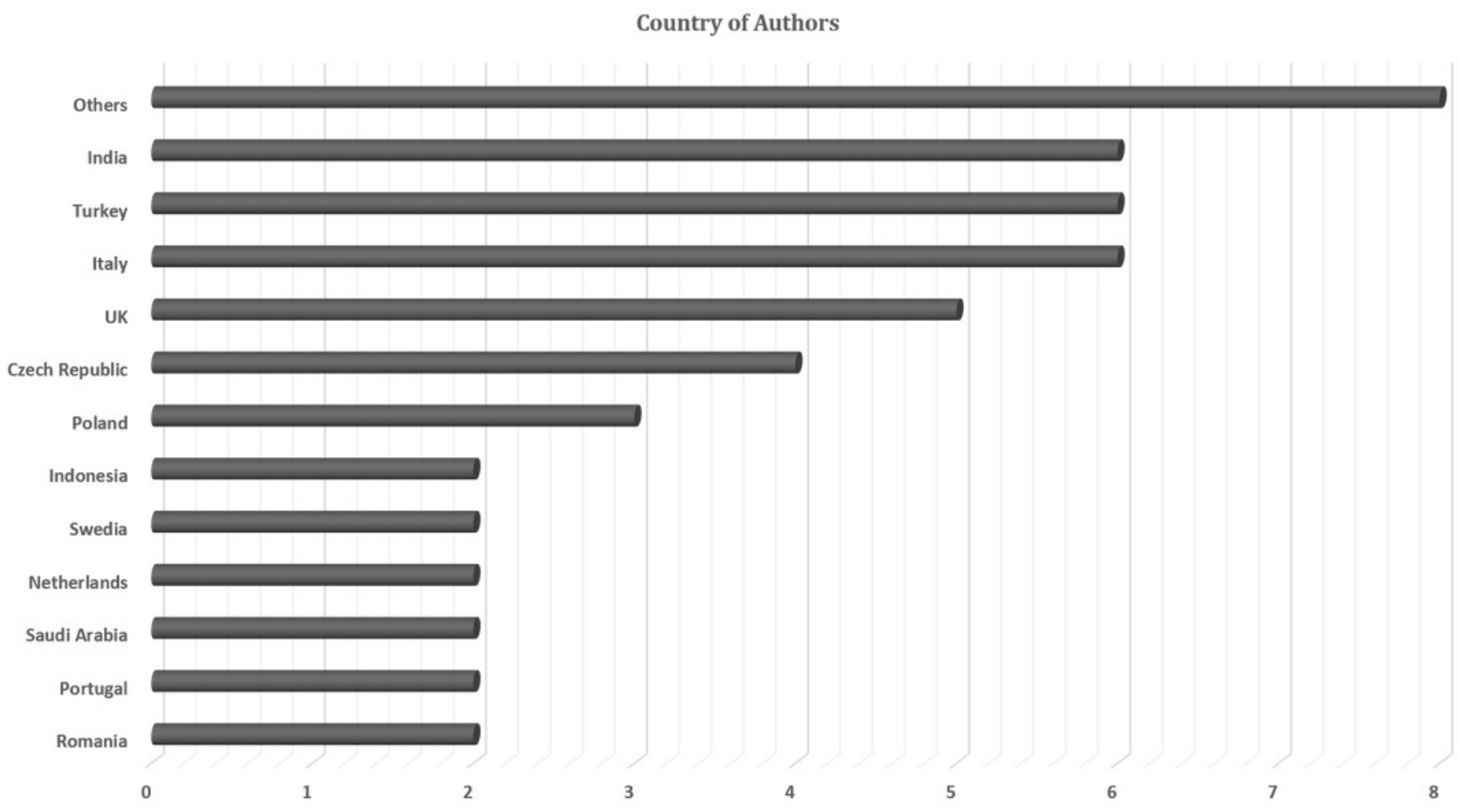




\title{
Figure 6
}

\section{Motivation categories of feature extraction and cardiotocography classification}

\author{
Motivation related to early detection and rapid diagnoses \\ - Prevent fetal brain damages \\ - To decipher the early signs of fetal hypoxia thus avoiding \\ further compression \\ - Preventing the maternal and fetal morbidity and mortality
}

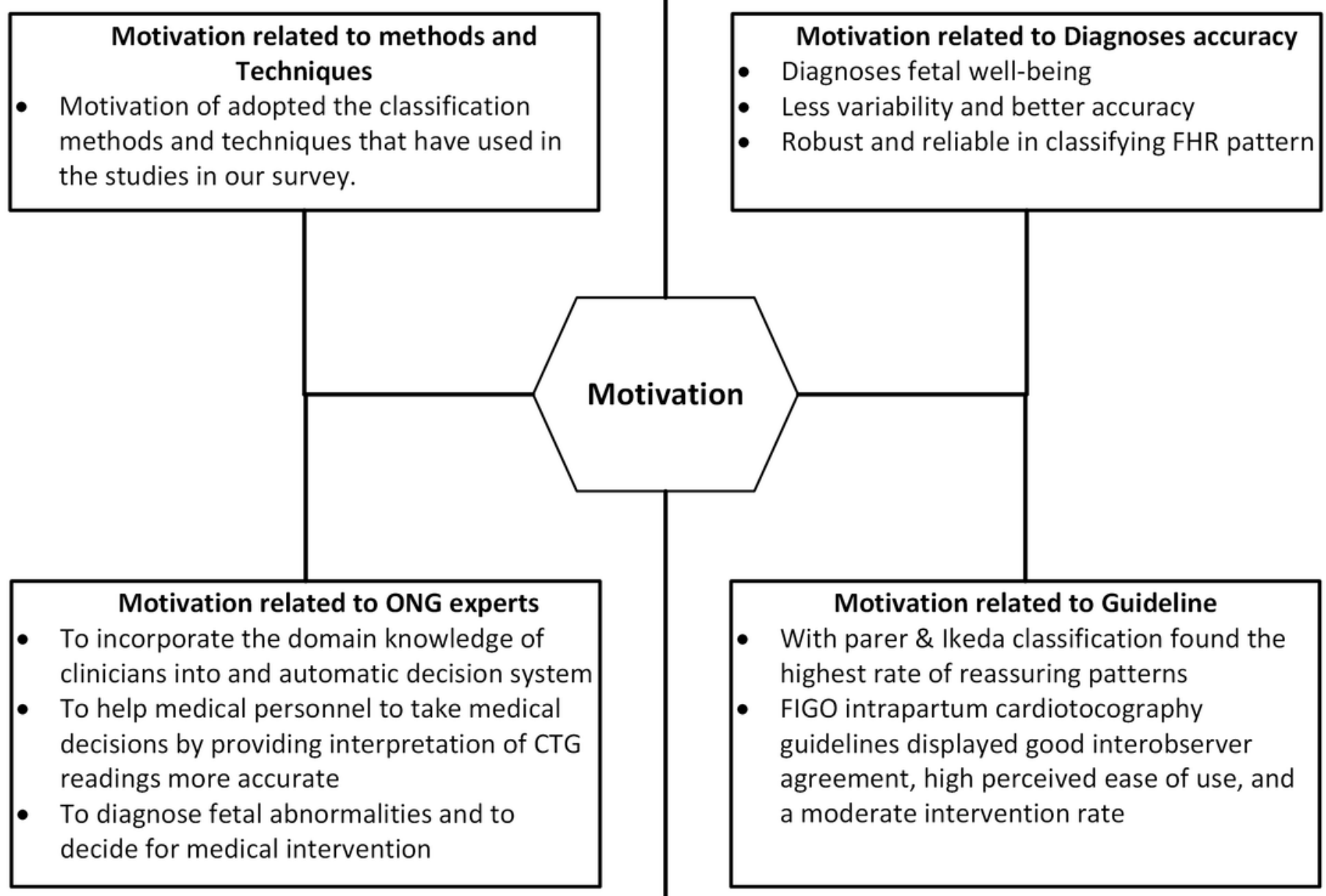

Motivation related to Datasets

- Larger testing dataset for better analysis 
Figure 7

Recommended categories of feature extraction and cardiotocography classification

\section{Recommendation for user}

- Guidelines help practitioners

- Understand the physiology behind FHR

- Check the maternal pulse

- Understanding the types of intrapartum fetal hypoxia and fetal reserve

- Better accuracy

\section{Accuracy recommendation}

- Preprocessing

- Feature extraction \& Feature selection

- Carefully Evaluated

- Great care

- Large Datasets

- Clinical information

- Different classification

Classification universally standardized

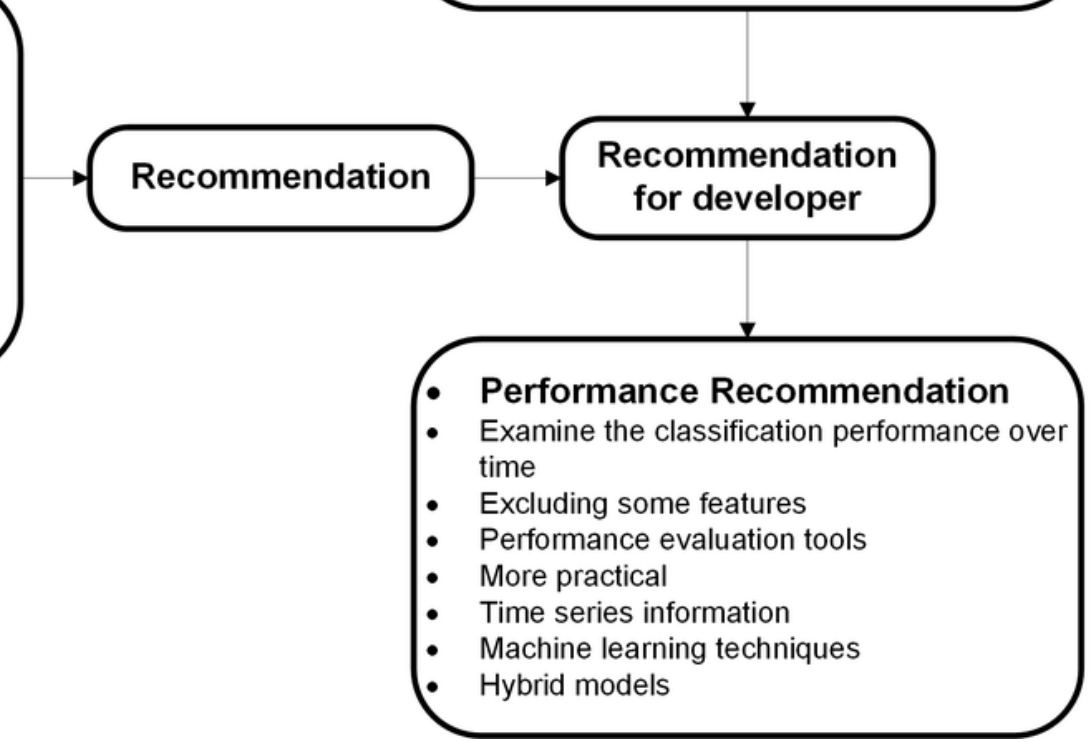




\section{Table 1 (on next page)}

Search query settings 
Tabel 1 Search query settings

\begin{tabular}{llll}
\hline Sources & IEEE & Science Direct & Web of Science \\
\hline Years & $2013-2018$ & $2013-2018$ & $2013-2018$ \\
\hline Languange & English & English & English \\
\hline Run on & Full Text & Full Text & Full Text \\
\hline Subject areas & All Available & All Available & All Available \\
\hline $\begin{array}{l}\text { Date of } \\
\text { running search }\end{array}$ & $17 / 03 / 2018$ & $17 / 03 / 2018$ & $20 / 03 / 2018$ \\
\hline
\end{tabular}

2

3 


\section{Table 2 (on next page)}

Dataset used in reviewed research 
Table 1 Dataset used in reviewed research

\begin{tabular}{|c|c|c|c|c|}
\hline No. & Ref & Datasets & Type & Source \\
\hline 1 & $\begin{array}{l}\text { [8], [6], [13], [9], } \\
{[1],[37],[22],} \\
{[15],[2],[3],[7],} \\
{[16],[19],[47],} \\
{[48],[25],[49]} \\
\end{array}$ & $\begin{array}{l}\text { Publicly } \\
\text { available }\end{array}$ & $\begin{array}{l}\text { Each record provides information } \\
\text { about morphological patterns } \\
\text { (physiological, suspect, } \\
\text { pathological) }\end{array}$ & $\begin{array}{l}\text { UCI Machine Repository } \\
\text { https://archive.ics.uci.edu/ml/datasets.ht } \\
\underline{\mathrm{ml}}\end{array}$ \\
\hline 2 & $\begin{array}{l}{[23],[31],[37],} \\
{[12],[11],[26]} \\
{[29]}\end{array}$ & $\begin{array}{l}\text { Publicly } \\
\text { available }\end{array}$ & $\begin{array}{l}\text { Consisting of } 552 \text { records obtained } \\
\text { between } 2009 \text { and } 2012\end{array}$ & $\begin{array}{l}\text { CTU-UHB database } \\
\text { From the midwifery ward of the university } \\
\text { hospital in Brno, Czech Republic } \\
\text { https://physionet.org/physiobank/databa } \\
\text { se/ctu-uhb-ctgdb/ }\end{array}$ \\
\hline 3 & [20], [28], & $\begin{array}{l}\text { Private } \\
\text { Datasets }\end{array}$ & $\begin{array}{l}\text { Intrapartum CTG has been routinely } \\
\text { monitored in HFME for the past } 30 \\
\text { years, with systematic monitoring } \\
\text { based on STAN }\end{array}$ & $\begin{array}{l}\text { Hospital Femme Mere Enfant (HFME) } \\
\text { (Lyon, France) } \\
\text { http://www.chu-lyon.fr/en/hopital- } \\
\text { femme-mere-enfant }\end{array}$ \\
\hline 4 & {$[4],[21],[26]$} & $\begin{array}{l}\text { Publicly } \\
\text { Available }\end{array}$ & Normal and Pathological datasets & $\begin{array}{l}\text { CTU-UHB } \\
\text { From Czech Technical University, } \\
\text { Department of Cybernatics } \\
\text { https://physionet.org/physiobank/databa } \\
\text { se/ctu-uhb-ctgdb/ }\end{array}$ \\
\hline 5 & [38] & $\begin{array}{l}\text { Private } \\
\text { Dataset }\end{array}$ & Normal fetuses and IUGRs & $\begin{array}{l}\text { Azienda Ospedaliera Universitaria } \\
\text { Federico II, Napoli, Italy }\end{array}$ \\
\hline 6 & [27] & $\begin{array}{l}\text { Private } \\
\text { Dataset }\end{array}$ & $\begin{array}{l}22 \text { cases were included with } \\
\text { adverse results, which was matched } \\
\text { with } 110 \text { healthy cases }\end{array}$ & $\begin{array}{l}\text { Registration of CTG is recorded at } \\
\text { Neoventa STAN (Molndal, Sweden) }\end{array}$ \\
\hline 7 & [46] & $\begin{array}{l}\text { Private } \\
\text { Dataset }\end{array}$ & $\begin{array}{l}\text { Retrospective nesting case-control } \\
\text { studies including a series of } \\
\text { consecutive fetuses delivered with } \\
\text { metabolic acidemia in the second } \\
\text { stage of labor between } 2008 \text { and } \\
2013\end{array}$ & University Hospital of Bologna \\
\hline 8 & [39] & $\begin{array}{l}\text { Private } \\
\text { Dataset }\end{array}$ & $\begin{array}{l}100 \text { and } 51 \text { CTG tracings were } \\
\text { consecutively selected from pre- } \\
\text { existing database of intrapartum } \\
\text { tracings. }\end{array}$ & Tertiary care University Hospital \\
\hline 9 & [36] & $\begin{array}{l}\text { Commer } \\
\text { cial } \\
\text { Dataset }\end{array}$ & $\begin{array}{l}\text { Recorded from healthy pregnant } \\
\text { women }\end{array}$ & Clinical Environment [36] \\
\hline 10 & [30] & $\begin{array}{l}\text { Commer } \\
\text { cial } \\
\text { Dataset }\end{array}$ & $\begin{array}{l}\text { All CTGs are recorded during } \\
\text { routine daily fetal monitoring in the } \\
\text { clinical environment of women } \\
\text { between } 31 \text { and } 41 \text { weeks of } \\
\text { gestation both on antepartum and } \\
\text { in intrapartum }\end{array}$ & Clinical Environment [30] \\
\hline 11 & [40] & $\begin{array}{l}\text { Private } \\
\text { Dataset }\end{array}$ & $\begin{array}{l}\text { Ninety-seven traces of the FHR } \\
\text { were selected among those } \\
\text { collected between June and }\end{array}$ & $\begin{array}{l}\text { Careggi University Hospital of Florence } \\
\text { (Tuscany, Italy) }\end{array}$ \\
\hline
\end{tabular}




\begin{tabular}{lllll}
\hline & & September 2009 & \\
\hline 12 & {$[43]$} & $\begin{array}{l}\text { Private } \\
\text { Dataset }\end{array}$ & $\begin{array}{l}\text { Sixty-two CTG searches with 20 to } \\
\text { 30-minutes of sections collected } \\
\text { from different pregnant women at } \\
\text { the time of entry to the delivery } \\
\text { room for labor pain }\end{array}$ & $\begin{array}{l}\text { Mackay Memorial Hospital, a tertiary } \\
\text { referral center }\end{array}$ \\
& & Private & $\begin{array}{l}\text { Datasets consists of 2126 } \\
\text { cardiotocograms }\end{array}$ & $\begin{array}{l}\text { Maternity and Gynecology Clinic (Porto } \\
\text { University Hospital in Portugal) }\end{array}$ \\
\hline 13 & {$[44]$} & Dataset & & \\
\hline
\end{tabular}

3 


\section{Table 3 (on next page)}

Model validation techniques used in the reviewed researches 
1 Table 1 Model validation techniques used in the reviewed researches

\begin{tabular}{|l|l|l|}
\hline No & Name of Validation Technique & Reference \\
\hline 1 & $\begin{array}{l}\text { Cross Validation (10 fold cross validation, k-fold } \\
\text { cross validation and 2 fold stratified cross } \\
\text { validation) }\end{array}$ & $\begin{array}{l}{[23],[13],[9],[1],[12],[38],[27],[11],[3],} \\
{[32],[24],[47],[41],[26],[28],[22], ~[7],} \\
{[48],[49],[44]}\end{array}$ \\
\hline 2 & Confidence interval & {$[4]$} \\
\hline 3 & Paired sample t-test & {$[4],[46]$} \\
\hline 4 & Bland-Altman approach & {$[4]$} \\
\hline 5 & Mann - Whitney test & {$[46]$} \\
\hline 6 & Kappa Statistics & {$[39],[45],[40],[43]$} \\
\hline
\end{tabular}

2

3 


\section{Table 4 (on next page)}

the performance measurement criteria implemented in the reviewed articles 
1 Table 1 the performance measurement criteria implemented in the reviewed articles

\begin{tabular}{|c|c|c|c|c|c|c|c|c|c|c|c|c|c|c|c|c|c|c|c|c|c|c|}
\hline \multirow{3}{*}{ 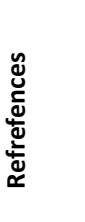 } & \multicolumn{15}{|c|}{ Reliability group } & \multirow{3}{*}{$\begin{array}{l}\frac{0}{\frac{0}{J}} \\
\frac{0}{0} \\
\frac{1}{5}\end{array}$} & \multirow{3}{*}{ 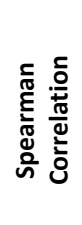 } & \multirow{3}{*}{$\stackrel{\bigcup}{2}$} & \multirow{3}{*}{ 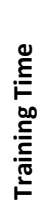 } & \multirow{3}{*}{ 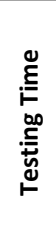 } & \multirow{3}{*}{ 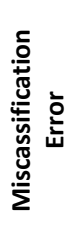 } & \multirow{3}{*}{ 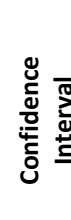 } \\
\hline & \multicolumn{4}{|c|}{ Confusion Matrix } & \multirow[b]{2}{*}{$\sum_{\propto}^{\breve{M}}$} & \multirow[b]{2}{*}{ 売 } & \multirow[b]{2}{*}{ 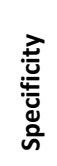 } & \multirow[b]{2}{*}{$\begin{array}{l}\frac{}{\mathfrak{n}} \\
\frac{0}{2} \\
\frac{0}{2}\end{array}$} & \multirow[b]{2}{*}{ 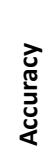 } & \multirow[b]{2}{*}{ : } & \multirow[b]{2}{*}{ 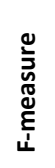 } & & & & & & & & & & & \\
\hline & $\begin{array}{l}\text { வீ} \\
\text { ㄴ }\end{array}$ & ’̊ํ & ஷ̊ํㄴ & 인 & & & & & & & & $\frac{\underline{\underline{T}}}{\frac{\pi}{\partial}}$ & 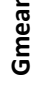 & $\underset{\Sigma}{\Psi}$ & $\sum_{<}^{\text {岁 }}$ & & & & & & & \\
\hline$[8]$ & $*$ & & & & & & & & $*$ & & & & & & & & & & & & & \\
\hline$[6]$ & & & & & $*$ & & & & & & & & & & & & & & & & & \\
\hline [23] & & & & & & & & & & & & & & & & $*$ & & & & & & \\
\hline [31] & $*$ & $*$ & $*$ & $*$ & & $*$ & $*$ & & & & & & & & & & $*$ & & & & & \\
\hline [13] & & & & & & & & $*$ & & $*$ & & & & & & & & & & & & \\
\hline [9] & & & & & & & & $*$ & & $*$ & $*$ & & & & & & & & & & & \\
\hline [21] & & & & & & & & & $*$ & & & & & & & & & & & & & \\
\hline$[1]$ & & & & & & & & & $*$ & & & & & & & & & $*$ & & & & \\
\hline [37] & $*$ & $*$ & $*$ & $*$ & & $*$ & $*$ & & $*$ & $*$ & & & & & & & & & $*$ & $*$ & & \\
\hline [12] & & & & & & & $*$ & & $*$ & $*$ & & & & & & & & & & & & \\
\hline [38] & $*$ & $*$ & $*$ & $*$ & & & & & $*$ & & & & & & & & & & & & & \\
\hline$[27]$ & . & & & & & & $*$ & & $*$ & $*$ & & & & & & & & & & & & \\
\hline [11] & $*$ & $*$ & $*$ & $*$ & & & $*$ & & $*$ & $*$ & & $*$ & & & & & & & & & & \\
\hline$[22]$ & & & & & & & & & $*$ & & & & $*$ & $*$ & $*$ & & & & & & & \\
\hline [10] & & & & & $*$ & & & & & & & & & $*$ & & & & & & & & \\
\hline [15] & & & & & & & & & & & & & & & & & & & & & $*$ & \\
\hline$[2]$ & & & & & & & & & $*$ & & & & & & & & & & & & & \\
\hline [3] & $*$ & $*$ & $*$ & $*$ & & & $*$ & $*$ & $*$ & $*$ & $*$ & $*$ & & & & & & $*$ & & & & \\
\hline [7] & $*$ & $*$ & $*$ & $*$ & & & $*$ & & $*$ & $*$ & $*$ & & & & & & & $*$ & & & & \\
\hline [46] & & & & & & & & & & & & & & & & & & $*$ & & & & $*$ \\
\hline [39] & & & & & & & & & $*$ & $*$ & & & & & & & & & & & & $*$ \\
\hline [36] & & & & & $*$ & & & & & & & & & & & & & & & & & \\
\hline [16] & & & & & & & & & $*$ & & & & & & & & & & & & & \\
\hline [32] & $*$ & $*$ & $*$ & $*$ & & & $*$ & & & $*$ & & & & & & & & & & & & \\
\hline [40] & & & & & & & & & & & & & & & & & & & & & & $*$ \\
\hline [17] & $*$ & $*$ & $*$ & $*$ & & & $*$ & & $*$ & $*$ & & $*$ & & & & & & & & & & \\
\hline [19] & & & & & & & & & $*$ & & & & & & & & & & & & & \\
\hline [18] & & & & & & & & & & & & $*$ & & & & & & & & & & \\
\hline [47] & $*$ & $*$ & $*$ & $*$ & & & & & $*$ & & & & & & & & & & & & & \\
\hline [41] & & & & & & & $*$ & & & $*$ & & & & & & & & & & & & \\
\hline [42] & & & & & & & $*$ & & & $*$ & & & & & & & & & & & & \\
\hline [26] & & & & & $*$ & & & & & & & & & & & & & & & & & \\
\hline [28] & & & & & & & $*$ & & & $*$ & & & & & & & & & & & & \\
\hline [48] & & & & & & & & $*$ & $*$ & $*$ & $*$ & & & & & & & & & & & \\
\hline [25] & & & & & & & $*$ & & & $*$ & $*$ & & & & & & & & & & & \\
\hline [49] & & & & & & & & & & $*$ & $*$ & & & & & & & & & & & \\
\hline [44] & & & & & & & & $*$ & $*$ & $*$ & $*$ & & & & & & & & & & & \\
\hline Total & 10 & 9 & 9 & 9 & 4 & 2 & 13 & 5 & 19 & 18 & 7 & 4 & 1 & 2 & 1 & 1 & 1 & 4 & 1 & 1 & 1 & 3 \\
\hline$\%$ & 20 & 18 & 18 & 18 & 8 & 4 & 26 & 10 & 38 & 36 & 14 & 8 & 2 & 4 & 2 & 2 & 2 & 8 & 2 & 2 & 2 & 6 \\
\hline
\end{tabular}




\section{Table 5 (on next page)}

Number of different guidelines occurrence in the study 
Tabel 5 Number of different guidelines occurrence in the study

\begin{tabular}{|l|l|l|}
\hline No. & FHR guidelines Types & Reference \\
\hline 1 & $\begin{array}{l}\text { FIGO (International Federation of Obstetrics } \\
\text { and Gynecology) }\end{array}$ & $\begin{array}{l}{[2],[4],[11],[13],[14],[17],[18][20],} \\
{[50]}\end{array}$ \\
\hline 2 & $\begin{array}{l}\text { NICHD (the National Institute of Child } \\
\text { Health Development) }\end{array}$ & {$[4],[21],[30],[39],[40],[42],[45]$} \\
\hline 3 & $\begin{array}{l}\text { NICE (National Institute of Health and Care } \\
\text { Excellence) }\end{array}$ & {$[5],[21],[35]$} \\
\hline 4 & $\begin{array}{l}\text { ACOG (the American College of } \\
\text { Obstetricians and Gynecologists) }\end{array}$ & {$[4],[21]$} \\
\hline 5 & $\begin{array}{l}\text { RCOG (the Royal College of Obstetricians } \\
\text { and Gynecologists) }\end{array}$ & {$[21],[46]$} \\
\hline 6 & $\begin{array}{l}\text { CNGOF (the French College of Gynecology } \\
\text { and Obstetrics) }\end{array}$ & {$[45]$} \\
\hline 7 & $\begin{array}{l}\text { NICHHD (the National Institute of Child } \\
\text { Health and Human Development) }\end{array}$ & {$[50]$} \\
\hline
\end{tabular}

2 


\section{Table 6(on next page)}

Motivation to adopt cardiotocography classification techniques and methods 
|Tabel 6 Motivation to adopt cardiotocography classification techniques and methods

\begin{tabular}{|c|c|c|}
\hline & $\begin{array}{l}\text { Methods \& } \\
\text { Techniques }\end{array}$ & Motivation \\
\hline 1 & Random Forest & $\begin{array}{l}\text { Random forest is widely used in statistical modeling techniques and one } \\
\text { of the most promising methods appears[8]. Random Forest has managed } \\
\text { to increase classification accuracy and accomplished better } \\
\text { generalization even for large databases in ensemble learning. }\end{array}$ \\
\hline 2 & $\begin{array}{l}\text { Volterra Neural } \\
\text { Network (VNN) }\end{array}$ & $\begin{array}{l}\text { VNN has fast and uniform convergence. Simulation has demonstrated } \\
\text { the efficiency of this techniques as proposed in electronic fetal } \\
\text { monitoring [6]. }\end{array}$ \\
\hline 3 & $\begin{array}{l}\text { A Novel Software } \\
\text { "CTG-OAS" }\end{array}$ & $\begin{array}{l}\text { [38] has introduced a new software called CTG-OAS for a comprehensive } \\
\text { analysis of CTG signals in this study. This software provides several tools } \\
\text { for conducting reliable analysis. Also, important procedures regarding } \\
\text { machine learning, such as feature extraction, pre-processing, } \\
\text { classification and feature selection, are inherent in the software. }\end{array}$ \\
\hline 4 & $\begin{array}{l}\text { Scattering } \\
\text { Transform }\end{array}$ & $\begin{array}{l}\text { Scattering transformation is proposed as a new tool for analyzing the } \\
\text { variability of intrapartum fetal heart rate (FHR). This consists of a } \\
\text { nonlinear extension of the underlying wavelet transformation, thereby } \\
\text { maintaining its multiscale nature [20]. }\end{array}$ \\
\hline 5 & Bagging Approach & $\begin{array}{l}\text { In this study, a bagging approach combined with three traditional } \\
\text { decision tree algorithms (random forest, Reduced Error Pruning Tree } \\
\text { (REPTree) and J48) has been applied to identify normal and pathological } \\
\text { fetal conditions using CTG data[20]. }\end{array}$ \\
\hline 6 & $\begin{array}{l}\text { Support Vector } \\
\text { Machine (SVM) }\end{array}$ & $\begin{array}{l}\text { SVM gives good accuracy [1] and has showed high performance for } \\
\text { binary classification with its ability to handle noisy data [2]. SVM } \\
\text { classification has become the most preferred techniques since its } \\
\text { introduction, and has been successfully used in many medical decision } \\
\text { support systems [16]. }\end{array}$ \\
\hline 7 & $\begin{array}{l}\text { Artitifical Neural } \\
\text { Network (ANN) }\end{array}$ & $\begin{array}{l}\text { ANN is a practical tool to solve many complex nature signal processing } \\
\text { problems, such as curve installation, pattern recognition and } \\
\text { classification, grouping and analysis of dynamic time series [37]. }\end{array}$ \\
\hline 8 & $\begin{array}{l}\text { Extreme Learning } \\
\text { Machine (ELM) }\end{array}$ & $\begin{array}{l}\text { ELM tends to provide good generalization performance with fast } \\
\text { learning speed in many cases and can learn thousands of times faster } \\
\text { than conventional learning [37]. }\end{array}$ \\
\hline 9 & $\begin{array}{l}\text { K Nearest } \\
\text { Neighbor }\end{array}$ & $\begin{array}{l}\text { The classification method based on } \mathrm{K} \text { Nearest Neighbor is presented for } \\
\text { automatic classification of various uterine construction during labor [12] } \\
\mathrm{K} \text { Nearest Neighbor is an example of a classification method with } \\
\text { parameter independence [7]. }\end{array}$ \\
\hline 10 & $\begin{array}{l}\text { The Adaptive } \\
\text { Boosting } \\
\text { (AdaBoost) }\end{array}$ & $\begin{array}{l}\text { Typical ensemble learning algorithms, this study proposed new design } \\
\text { concepts and make great success in many different practical applications } \\
\text { [3]. }\end{array}$ \\
\hline 11 & $\begin{array}{l}\text { Fuzzy Classification } \\
\text { System }\end{array}$ & $\begin{array}{l}\text { The possibility of assessing the efficient state of the fetus using the } \\
\text { proposed fuzzy inference method [17]. }\end{array}$ \\
\hline 12 & $\begin{array}{l}\text { Sparse Support } \\
\text { Vector Machine } \\
\text { (Sparse-SVM) }\end{array}$ & $\begin{array}{l}\text { Permits to select a small number of relevant features and to achieve } \\
\text { efficient fetal acidosis detection[28]. }\end{array}$ \\
\hline
\end{tabular}




\section{Table 7 (on next page)}

Challenge categories of feature extraction and cardiotocography classification 
Table 7 Challenge categories of feature extraction and cardiotocography classification

\begin{tabular}{|c|c|}
\hline $\begin{array}{l}\text { Challenge related to } \\
\text { algorithm }\end{array}$ & $\begin{array}{l}\text { - The REPTree algorithm has low accuracy especially in the accuracy of } \\
\text { suspected pathological status for small training sets. }\end{array}$ \\
\hline $\begin{array}{l}\text { Challenge related to } \\
\text { diagnosis }\end{array}$ & $\begin{array}{l}\text { - The knowledge and experience of the doctor largely influences } \\
\text { accuracy; } \\
\text { - Increasing cesarean delivery rates is one of the main reasons caused by } \\
\text { a lack of information provided by cardiotocography; } \\
\text { - The available evidence about the accuracy and efficacy of this system } \\
\text { is still limited. }\end{array}$ \\
\hline $\begin{array}{l}\text { Challenge related to } \\
\text { guidelines }\end{array}$ & $\begin{array}{l}\text { - In the guidelines there is still lack of objective explanations for some } \\
\text { features of fetal heart rate; } \\
\text { - The existing guidelines have deficiencies in terms of uniformity and } \\
\text { uncertainty, therefore it is difficult to implement automatic systems; } \\
\text { - There is still lack of precision, leading to differences of opinion among } \\
\text { medical practitioners; } \\
\text { - FIGO results poor specificity; } \\
\text { - guidelines have not become more simple or more objective; } \\
\text { - Differ in the terminology used; } \\
\text { - NICHD system was rapidly criticized by some investigators; } \\
\text { - The usefulness of NICHD system is under debate; } \\
\text { - no evidence of NICHD effectiveness. }\end{array}$ \\
\hline $\begin{array}{l}\text { Challenge related to } \\
\text { features }\end{array}$ & $\begin{array}{l}\text { - Many different pattern in the gray zone; } \\
\text { - Baseline is the most basic feature of FHR; } \\
\text { - The missing value problem is another problem that needs to be } \\
\text { resolved; } \\
\text { - Features extracted from histogram data are less important; } \\
\text { - very difficult to assess; } \\
\text { - Complex FHR patterns are assessed with eyes that are prone to errors, } \\
\text { inconsistent and unreliable; } \\
\text { - The complexity of patterns describing the FHR variability makes the } \\
\text { visual signal interpretation difficult and the accuracy of the analysis } \\
\text { depends mostly on clinician's knowledge and experience; } \\
\text { - The UA signal is often of poor quality. }\end{array}$ \\
\hline $\begin{array}{l}\text { Challenge related to } \\
\text { waveform }\end{array}$ & $\begin{array}{l}\text { - The FHR waveform has a complex form; } \\
\text { - The FHR waveform is a source of a lot of information, only a small } \\
\text { portion can be extracted by visual analysis; } \\
\text { - Heart rate signals often show complex and irregular fluctuations. }\end{array}$ \\
\hline $\begin{array}{l}\text { Challenge related to } \\
\text { dimensionality }\end{array}$ & $\begin{array}{l}\text { - The high dimension of CTG data are the problem for classification } \\
\text { computation; } \\
\text { - There is no guarantee that dimensions are higher and computing time } \\
\text { is greater; } \\
\text { - K-SVM reduces the feature dimension, however features of other data } \\
\text { with similar samples are not reduced. }\end{array}$ \\
\hline Challenge related to & - Increased birth by caesarean section and less specific in detecting \\
\hline
\end{tabular}




\begin{tabular}{|c|c|}
\hline CTG interpretation & $\begin{array}{l}\text { acidosis; } \\
\text { - Subjective interpretation and tedious technique; } \\
\text { - Poor specificity, not always possible; } \\
\text { - Unnecessary intervention; } \\
\text { - Poor positive predictive value; } \\
\text { - no standardization in the interpretation of the information; } \\
\text { - because the fetus is in the womb, several measurement problems arise; } \\
\text { - high complexity of signal patterns, which results in high levels of intra } \\
\text { - } \text { and interobserver variability; } \\
\text { - Conventional visual CTG interpretation is limited. }\end{array}$ \\
\hline $\begin{array}{l}\text { Challenge related to } \\
\text { classification }\end{array}$ & $\begin{array}{l}\text { - The FHR pattern classification still needs further improvement; } \\
\text { - Ignoring the suspect cases; } \\
\text { - Piquard classification was not applicable; } \\
\text { - The risk of a false classification of pathological cases remains high; } \\
\text { - The predictive capacity of the existing methods remains inaccurate; } \\
\text { - Traditional unsupervised methods provide very poor accuracy in } \\
\text { predicting different classes. }\end{array}$ \\
\hline $\begin{array}{l}\text { Challenge related to } \\
\text { time of diagnosis }\end{array}$ & $\begin{array}{l}\text { - Training time and test time takes longer; } \\
\text { - SVM consumes a lot of computational time }\end{array}$ \\
\hline $\begin{array}{l}\text { Challenge related to } \\
\text { ONG experts }\end{array}$ & $\begin{array}{l}\text { - Expertise is not always available, making CTG evaluation a difficult } \\
\text { task; } \\
\text { - Interpretation of CTG data after visual analysis performed by } \\
\text { obstetricians cannot be objective; } \\
\text { - the agreement between clinicians was moderate } \\
\text { - CTG recordings are analyzed by experts visually who make subjective } \\
\text { interpretations and cannot be reproduced. }\end{array}$ \\
\hline $\begin{array}{l}\text { Challenge related to } \\
\text { technical challege }\end{array}$ & $\begin{array}{l}\text { - The FHR record suffers from samples that are often invalid or lost, due } \\
\text { to sensor artifacts or error functions; } \\
\text { - great inter- and intra-observer variability; } \\
\text { - Lack of patients identification still occurs in } 8 \% \text { of antepartum } \\
\text { searches and } 31 \% \text { of intrapartum searches. }\end{array}$ \\
\hline $\begin{array}{l}\text { Challenge related to } \\
\text { dataset }\end{array}$ & $\begin{array}{l}\text { - Data interpretation ambiguity; } \\
\text { - Lack of late acceleration in the dataset; } \\
\text { - could not be objective and reproducible; } \\
\text { - Outlier value problem. }\end{array}$ \\
\hline $\begin{array}{l}\text { Challenge related to } \\
\text { evaluation }\end{array}$ & $\begin{array}{l}\text { - The classification uses a measure of performance evaluation, but it is } \\
\text { not enough to decide for a vital case especially in a medical diagnosis; } \\
\text { - fetal hypoxia is only about } 30 \% \text { of the positive predictive value for } \\
\text { intrapartum cases; } \\
\text { - There has been a effective increase in surgical birth rate and } \\
\text { intrapartum cesarean section; } \\
\text { - The standard definition of FHR variability (FHRV) and agreement on } \\
\text { the methodology that will be used in its evaluation is still lacking; }\end{array}$ \\
\hline
\end{tabular}


- ANN is still not accepted as a valid tool

- One of the main disadvantages of Tocography is subjectivity in interpretation and has high frequency noise due to sudden movements during recording. 